\title{
Somatotopic Representation of Second Pain in the Primary Somatosensory Cortex of Humans and Rodents
}

\author{
Q.Q. Jin, ${ }^{1,2 \star}$ G.Q. Wu ${ }^{1,2 \star}$ W.W. Peng, ${ }^{3}$ X.L. Xia, ${ }^{1,2}$ L. Hu, ${ }^{1,2 \dagger}$ and G.D. Iannetti ${ }^{4,5} 5^{\dagger}$ \\ ${ }^{1}$ CAS Key Laboratory of Mental Health, Institute of Psychology, Beijing, 100101, China, ${ }^{2}$ Department of Psychology, University of Chinese Academy of Sciences, \\ Beijing 100049, China, ${ }^{3}$ Brain Function and Psychological Science Research Center, Shenzhen University, Shenzhen 518060, China, ${ }^{4}$ Department of Neuroscience, \\ Physiology and Pharmacology, University College London, London WC1E 6BT, United Kingdom, and 5Istituto Italiano di Tecnologia, 16163 Genova, Italy
}

There is now compelling evidence that selective stimulation of A $\delta$ nociceptors eliciting first pain evokes robust responses in the primary somatosensory cortex (S1). In contrast, whether the C-fiber nociceptive input eliciting second pain has an organized projection to S1 remains an open question. Here, we recorded the electrocortical responses elicited by nociceptive-specific laser stimulation of the four limbs in 202 humans (both males and females, using EEG) and 12 freely moving rats (all males, using ECoG). Topographical analysis and source modeling revealed in both species, a clear gross somatotopy of the unmyelinated C-fiber input within the S1 contralateral to the stimulated side. In the human EEG, S1 activity could be isolated as an early-latency negative deflection (C-N1 wave peaking at $710-730$ $\mathrm{ms}$ ) after hand stimulation, but not after foot stimulation because of the spatiotemporal overlap with the subsequent large-amplitude supramodal vertex waves (C-N2/P2). In contrast, because of the across-species difference in the representation of the body surface within $\mathrm{S} 1, \mathrm{~S} 1$ activity could be isolated in rat ECoG as a C-N1 after both forepaw and hindpaw stimulation. Finally, we observed a functional dissociation between the generators of the somatosensory-specific lateralized waves (C-N1) and those of the supramodal vertex waves (C-N2/P2), indicating that $\mathrm{C}$-fiber unmyelinated input is processed in functionally distinct somatosensory and multimodal cortical areas. These findings demonstrated that $\mathrm{C}$-fiber input conveys information about the spatial location of noxious stimulation across the body surface, a prerequisite for deploying an appropriate defensive motor repertoire.

Key words: C fibers; electrocorticography (ECoG); electroencephalography (EEG); multispecies investigations; pain; primary somatosensory cortex $(\mathrm{S} 1)$

\section{Significance Statement}

Unmyelinated C-fibers are the evolutionarily oldest peripheral afferents responding to noxious environmental stimuli. Whether C-fiber input conveys information about the spatial location of the noxious stimulation to the primary somatosensory cortex (S1) remains an open issue. In this study, C-fibers were activated by radiant heat stimuli delivered to different parts of the body in both humans and rodents while electrical brain activity was recorded. In both species, the C-fiber peripheral input projects to different parts of the contralateral S1, coherently with the representation of the body surface within this brain region. These findings demonstrate that $\mathrm{C}$-fiber input conveys information about the spatial location of noxious stimulation across the body surface, a prerequisite for deploying an appropriate defensive motor repertoire.

\section{Introduction}

Because of the different conduction velocity of $\mathrm{A} \delta(\sim 15 \mathrm{~m} / \mathrm{s})$ and $\mathrm{C}(\sim 1 \mathrm{~m} / \mathrm{s})$ afferents, a single and intense cutaneous nociceptive stimulus elicits a typical double sensation: an initial A $\delta$-fiber-related pricking "first" pain is followed by a C-fiber-related burning "second" pain (Lewis and Pochin, 1937; Basbaum and Bushnell, 2009).
Received Dec. 13, 2017; revised Feb. 26, 2018; accepted April 7, 2018.

Author contributions: L.H. and G.D.I. designed research; Q.Q.J., G.Q.W., W.W.P., X.L.X., and L.H. performed research; Q.Q.J., G.Q.W., W.W.P., X.L.X., L.H., and G.D.I. analyzed data; Q.Q.J., L.H., and G.D.I. wrote the paper.

This work was supported by the National Natural Science Foundation of China (Grants 31471082 and 31671141 to L.H.), the Scientific Foundation project of Institute of Psychology, Chinese Academy of Sciences (Grant Y6CX021008 to L.H.), the 13th Five-year Informatization Plan of Chinese Academy of Sciences (Grant XXH13506 to L.H.), the Wellcome Trust (PAIN JLARAXR to G.D.I.), and the European Research Council (PAINSTRAT Consolidator Grant to G.D.I.). G.D.I. is additionally supported by a fellowship at the Paris Institute for Advanced Studies.

The authors declare no competing financial interests.
${ }^{*}$ Q.Q.J. and G.Q.W. contributed equally to this work.

tL.H. and G.D.I. are co-senior authors.

Correspondence should be addressed to Dr. Li Hu, Key Laboratory of Mental Health, Institute of Psychology, Chinese Academy of Sciences, Beijing, China, 100101. E-mail: huli@psych.ac.cn.

DOI:10.1523/JNEUROSCI.3654-17.2018

Copyright $\odot 2018$ Jin, Wu et al.

This is an open-access article distributed under the terms of the Creative Commons Attribution License Creative Commons Attribution 4.0 International, which permits unrestricted use, distribution and reproduction in any medium provided that the original work is properly attributed. 
In humans, the brain electrical responses elicited by laser heat pulses that concomitantly activate $\mathrm{A} \delta$ - and C-fiber endings in the superficial skin layers (laser-evoked brain potentials, LEPs) (Bromm and Treede, 1984) show clear deflections at latencies compatible with the conduction velocity of $\mathrm{A} \delta$-fibers (A $\delta$-LEPs or late LEPs; Treede et al., 1988). The largest deflection is a negative-positive complex (N2-P2) maximal at the scalp vertex, peaking at $\sim 200-$ $350 \mathrm{~ms}$ when stimulating the hand dorsum (Bromm and Treede, 1984). This N2-P2 complex is functionally similar to the vertex potentials elicited by sudden stimuli belonging to non-nociceptive sensory modalities (Mouraux and Iannetti, 2009) and largely reflects supramodal saliency-related neural processes, possibly consequent to the detection of behaviorally relevant changes in the sensory environment (Downar et al., 2000). The N2-P2 vertex complex is preceded by a smaller negative deflection (N1), which, when stimulating the hand dorsum, peaks at $\sim 160 \mathrm{~ms}$ and is maximal over the central temporal region contralateral to the stimulated side (Tarkka and Treede, 1993). The early contralateral N1 wave of the A $\delta$-LEPs reflects somatosensory-specific activity more related to the magnitude of the incoming nociceptive input (Lee et al., 2009). This somatosensory-specific activity is likely to subserve the high spatial acuity for first pain (Mancini et al., 2013), as indicated by the existence of fine-grained maps of $A \delta$ nociceptive input to individual digits in the human primary somatosensory cortex (S1) (Mancini et al., 2012).

In contrast, the EEG deflections related to the activation of C-fibers (C-LEPs or ultralate LEPs; Iannetti et al., 2003) are more difficult to detect. C-LEPs have initially been suggested to appear only when the concomitant activation of $\mathrm{A} \delta$-fibers is avoided or reduced (Bromm and Treede, 1983; Bragard et al., 1996; Mouraux et al., 2003) because the low intensity and high temporal predictability of the C-fiber input make it less salient than the preceding A $\delta$ input (Iannetti et al., 2008; Mouraux and Iannetti, 2009; Ronga et al., 2013). However, we recently showed that by applying advanced signal processing techniques (e.g., peak alignment and time-frequency decomposition) and using optimal stimulus parameters (e.g., delivering a high number of stimuli of multiple energies within a small skin territory), the N2-P2 vertex complex can be reliably detected in single-subject C-LEPs, even when preceded by A $\delta$-LEPs (Hu et al., 2014b).

Different from humans, A $\delta$ afferents are virtually insensitive to heat in rodents (Lynn and Shakhanbeh, 1988; Shim et al., 2005). Therefore, the same laser heat pulses that coactivate $\mathrm{A} \delta$ and C-fiber endings in primates (Treede et al., 1998; Magerl et al., 1999) almost uniquely activate C-fiber afferents when delivered to the rat skin (Sikandar et al., 2013; Hess, 2015; Hu et al., 2015). Therefore, both pain-related behavior and central responses elicited by laser pulses in rats occur at latencies only compatible with the activation of C-fiber primary afferents (Sikandar et al., 2013; Xia et al., 2016).

Here, we tested whether the C-fiber input has a somatotopically organized projection to the $\mathrm{S} 1$ in humans and rodents. We recorded 64-channel EEG responses elicited by laser stimulation of the four limbs in 202 healthy human participants. We also recorded 14-channel ECoG responses elicited by the same laser stimulation of the four paws in 12 awake and freely moving rats. We used topographical analysis and source modeling both at group and single-subject level to test the working hypothesis. Furthermore, the concomitant presence of both A $\delta$-LEPs and C-LEPs in human recordings allowed us to perform a comprehensive correlation analysis of the different deflections. With this analysis, we explored the functional relationship between somatosensory-specific and supramodal generators of the brain responses evoked by C-fiber input.

\section{Materials and Methods}

\section{Experiment 1: Human EEG during hand stimulation}

Subjects. EEG data were collected from 107 healthy subjects (67 females) aged $21.6 \pm 1.8$ years (mean $\pm \mathrm{SD}$, range $=18-26$ years). All subjects gave their written informed consent and were paid for their participation. The local ethics committee approved the experiment procedures.

Nociceptive stimulation. Nociceptive-specific radiant heat stimuli were generated by an infrared neodymium yttrium aluminum perovskite ( $\mathrm{Nd}$ : YAP) laser with a wavelength of $1.34 \mu \mathrm{m}$ (Electronical Engineering). At this wavelength, laser pulses activate epidermal nociceptive terminals belonging to $\mathrm{A} \delta$ and $\mathrm{C}$ primary nociceptors directly (Iannetti et al., 2003). Laser pulses were delivered at the dorsum of the left hand (LH) and right hand $(\mathrm{RH})$ on a squared area $\left(5 \times 5 \mathrm{~cm}^{2}\right)$ defined before the beginning of the experimental session. An $\mathrm{He}-\mathrm{Ne}$ laser pointed to the area to be stimulated. The laser pulse was transmitted via an optic fiber and its diameter was set at $\sim 7 \mathrm{~mm}\left(\sim 38 \mathrm{~mm}^{2}\right)$ by focusing lenses. The duration of the laser pulse was $4 \mathrm{~ms}$. To allow for passive skin cooling and avoid nociceptor fatigue or sensitization, the laser beam target was shifted by $\sim 1 \mathrm{~cm}$ in a random direction after each stimulus. After each stimulus, subjects were instructed to rate the intensity of perceived pain on a 0-10 numerical rating scale (NRS), with 0 standing for "no sensation" and 10 standing from "pain as bad as it could possibly be."

Experimental design. Before the EEG data collection, for each subject, we identified the 4 laser energies that evoked subjective pain ratings of $\sim 2, \sim 4, \sim 6$, and $\sim 8$ on the $0-10$ NRS by increasing the stimulus energy in steps of $0.25 \mathrm{~J}$ until the target rating was reached. Across the group, these energies were as follows: E1, $2.0 \pm 0.2 \mathrm{~J}$; E2, $2.7 \pm 0.3 \mathrm{~J}$; E3, $3.4 \pm 0.3$ $\mathrm{J}$; and E4, $4.1 \pm 0.4 \mathrm{~J}$. The experiment consisted of two blocks. In each block, laser stimuli were delivered to the dorsum of either the left hand (LH) or the right hand (RH). In each block, 10 laser pulses of each stimulus energy were delivered, for a total of 40 pulses per stimulation side ( 80 pulses in total). The order of blocks was counterbalanced across subjects and the order of stimulus energies was pseudorandomized. The surface temperature of the stimulated hand dorsum was measured before each block using an infrared thermometer, to ensure that the difference between the two blocks was never $>1{ }^{\circ} \mathrm{C}$ (Iannetti et al., 2004; Baumgärtner et al., 2005). This temperature was $33.3 \pm 1.1^{\circ} \mathrm{C}$ and $33.4 \pm 1.1^{\circ} \mathrm{C}$ before each block, respectively $\left(t_{(106)}=-0.87, p=0.39\right.$, paired-samples $t$ test). An auditory tone was delivered randomly between 3 and $6 \mathrm{~s}$ after the laser stimulation to prompt subjects to rate the intensity of pain perception elicited by the laser stimulus on the same 0-10 NRS. The interstimulus interval varied randomly between 11 and $15 \mathrm{~s}$ using a rectangular distribution.

EEG recording. Subjects were seated in a comfortable chair in a silent, temperature-controlled room and wore protective goggles. They were asked to focus their attention on the stimuli, relax their muscles, and keep their eyes open and gaze slightly downward. EEG data were recorded using $64 \mathrm{Ag}-\mathrm{AgCl}$ electrodes placed on the scalp according to the International 10-20 system, using the nose as reference (Brain Products; pass band: 0.01-100 Hz; sampling rate: $1000 \mathrm{~Hz}$ ). Electrode impedances were kept $<10 \mathrm{k} \Omega$. To monitor ocular movements and eye blinks, EOG signals were simultaneously recorded from two surface electrodes, one placed over the lower eyelid and the other placed $1 \mathrm{~cm}$ lateral to the outer corner of the orbit.

EEG data analysis. EEG data were processed using EEGLAB (Delorme and Makeig, 2004), an open source toolbox running in the MATLAB environment (The MathWorks). Continuous EEG data were band-pass filtered between 1 and $30 \mathrm{~Hz}$. EEG epochs were extracted using a window analysis time of $3000 \mathrm{~ms}$ ( $1000 \mathrm{~ms}$ prestimulus and $2000 \mathrm{~ms}$ poststimulus) and baseline corrected using the prestimulus interval. Based on visual inspection, trials contaminated by artifacts due to gross movements were removed. In addition, trials contaminated by eye blinks and movements were corrected using an independent component analysis (ICA) algorithm (Delorme and Makeig, 2004). In all datasets, these indepen- 
dent components (ICs) had a large EOG channel contribution and a frontal scalp distribution. After preprocessing, EEG data were rereferenced to the common average.

Across four stimulus energies (E1-E4), epochs belonging to the same stimulation side ( $\mathrm{LH}$ or $\mathrm{RH}$ ) were averaged time-locked to stimulus onset, thus yielding two average waveforms for each subject. Peak latencies and amplitudes of $\mathrm{A} \delta-\mathrm{N} 2, \mathrm{~A} \delta-\mathrm{P} 2, \mathrm{C}-\mathrm{N} 2$, and $\mathrm{C}-\mathrm{P} 2$ waves were measured from single-subject average waveforms ( $\mathrm{Cz}$-average). $\mathrm{A} \delta$ - $\mathrm{N} 2$ and $\mathrm{A} \delta$-P2 waves were defined as the most negative and positive deflections between 150 and $500 \mathrm{~ms}$ after stimulus onset (Kunde and Treede, 1993; Tu et al., 2016). C-N2 and C-P2 waves were defined as the most negative and positive deflections between 700 and $1300 \mathrm{~ms}$ after stimulus onset (Hu et al., 2014b). Single-subject average waveforms were subsequently averaged to obtain group-level waveforms. Group-level scalp topographies at the peak latency of the $\mathrm{A} \delta-\mathrm{N} 2, \mathrm{~A} \delta-\mathrm{P} 2, \mathrm{C}-\mathrm{N} 2$, and C-P2 waves were computed by spline interpolation.

Statistical analysis. To explore the spatial differences between the response elicited by the stimulation of the $\mathrm{LH}$ and $\mathrm{RH}$, we plotted the scalp topographies of the earliest part of A $\delta$-LEPs (i.e., from 150-170 ms, corresponding to the $\mathrm{A} \delta$-N1) and of C-LEPs (i.e., from $710-730 \mathrm{~ms}$, corresponding to the $\mathrm{C}-\mathrm{N} 1$ ), in steps of $10 \mathrm{~ms}$. To test whether these earliest responses were lateralized with respect to the stimulated hand, we compared single-subject LEP waveforms elicited by the stimulation of the LH and RH using the following procedure (Hu et al., 2014a). First, for each subject and each stimulation side, LEP waveforms were normalized and expressed as $Z$-values by subtracting from each time point the mean amplitude of the waveform and then dividing the resulting value by the SD of the waveform amplitude. Second, a point-by-point paired-samples $t$ test was used to compare LEP responses elicited by stimulation of the $\mathrm{LH}$ and $\mathrm{RH}$ dorsum, which yielded a time course of $p$-values representing the significance of the difference between LEPs elicited by LH and RH stimulation for each electrode. Third, to account for multiple comparisons of different time points and electrodes, a false discovery rate (FDR) (Benjamini and Hochberg, 1995) procedure was used to correct the significance level ( $p$-value). Fourth, single-subject difference LEP waveforms ( $\mathrm{LH}-\mathrm{RH})$ were calculated and averaged across subjects, to display the group-level difference of LEPs elicited by stimulation of the LH and $\mathrm{RH}$ dorsum.

To estimate the locations of A $\delta$-N1 and C-N1 sources, group-level LEP waveforms were imported in Brain Electrical Source Analysis Software (BESA 5.3; MEGIS Software). Sources of LEP waveforms were modeled using equivalent current dipoles from a spatiotemporal source model (Scherg and Ebersole, 1993; Lopes da Silva, 2004). Based on findings of several previous studies (e.g., Garcia-Larrea et al., 2003; Valentini et al., 2012), a four-dipole model was used. Dipole configurations were calculated within a realistic head model and estimated according to the best correspondence between the recorded and estimated scalp distribution. The ability of the estimated dipoles to explain satisfactorily the recorded scalp topography was expressed as the signal residual variance; that is, the percentage of the scalp data that cannot be explained by the fitted dipoles. For each dipole, the location, orientation, and time course were extracted and source locations were transformed to normalized Talairach space.

Because of the contralateral scalp distribution of the early LEP activity (i.e., $\mathrm{A} \delta$-N1 and $\mathrm{C}-\mathrm{N} 1$ ), to measure the amplitudes of $\mathrm{A} \delta$-N1 and $\mathrm{C}-\mathrm{N} 1$ waves, we used a bipolar montage consisting of the contralateral central electrode referenced to Fz (Cc-Fz) (Hu et al., 2010; Valentini et al., 2012). From the single-subject Cc-Fz rereferenced LEP waveform averaged across trials and stimulus energies, peak latencies and amplitudes of $\mathrm{A} \delta$-N 1 and $\mathrm{C}-\mathrm{N} 1$ waves were measured manually for each subject (if a clear response could not be detected, then default values, "NaN," were assigned). A $\delta$-N1 and $\mathrm{C}-\mathrm{N} 1$ were defined as the negative deflections preceding the $\mathrm{A} \delta$ - $\mathrm{N} 2$ and $\mathrm{C}-\mathrm{N} 2$ waves, respectively (Tarkka and Treede, 1993; Valentini et al., 2012). Only unique and clear negative deflections preceding the $\mathrm{A} \delta$-N2 $(\mathrm{C}-\mathrm{N} 2)$ waves were classified as $\mathrm{A} \delta-\mathrm{N} 1(\mathrm{C}-\mathrm{N} 1)$ responses [A $\delta$-N1: $81.3 \%$ of subjects (both $\mathrm{LH}$ and $\mathrm{RH}$ ); C-N1: $72.9 \%$ $(\mathrm{LH})$ and $75.7 \%(\mathrm{RH})]$. A $\delta$-N1 $(\mathrm{C}-\mathrm{N} 1)$ responses were defined as absent if the $\mathrm{A} \delta$-N1 (C-N1) amplitude was positive or if a clear negative deflection preceding the $\mathrm{A} \delta$-N2 (C-N2) wave could not be identified (Hu et al., 2010). Single-subject LEP waveforms (Cc-Fz) were subsequently aver- aged to obtain group-level rereferenced waveforms. Group-level scalp topographies at the peak latencies of $\mathrm{A} \delta$-N1 and $\mathrm{C}-\mathrm{N} 1$ waves were computed by spline interpolation.

To explore the functional relationship between the $\mathrm{C}-\mathrm{N} 1$ and the other LEP waves, latencies and amplitudes of $\mathrm{C}-\mathrm{N} 1$ wave were correlated with those of other LEP waves (i.e., A $\delta$-N1, A $\delta$-N2, A $\delta$-P2, C-N2, and C-P2 waves) across subjects using Pearson's correlation analysis. To account for multiple comparisons, $p$-values were adjusted using FDR correction.

Furthermore, to assess the dependence of $\mathrm{A} \delta$-N1 and C-N1 amplitudes on stimulus energy, we calculated the averaged LEP waveform for each level of stimulus energy, thus obtaining four average waveforms (E1-E4) for each stimulated hand ( $\mathrm{LH}$ and $\mathrm{RH}$ ). Peak amplitudes of $\mathrm{A} \delta$-N 1 and $\mathrm{C}-\mathrm{N} 1$ waves at each stimulus energy were measured from the waveforms $(\mathrm{Cc}-\mathrm{Fz})$ of each subject. $\mathrm{A} \delta-\mathrm{N} 1$ and $\mathrm{C}-\mathrm{N} 1$ amplitudes were compared statistically using a two-way repeated-measures ANOVA, with stimulation site (two levels: $\mathrm{LH}$ and RH) and stimulus energy (four levels: E1-E4) as within-subject factors. When significant, post hoc comparisons were performed using paired-samples $t$ tests.

To assess the dependence of $\mathrm{A} \delta$ - $\mathrm{N} 1$ and $\mathrm{C}-\mathrm{N} 1$ amplitudes on perceived pain intensity, we classified single trials in four categories (I1-I4) according to the subjective pain ratings. This was achieved by first rescaling the ratings of each subject between 0 and 100, defining the smallest pain rating as 0 and the largest pain rating as 100 (Zhang et al., 2012). For each subject and each stimulated hand ( $\mathrm{LH}$ and $\mathrm{RH})$, trials were then classified in four categories $(\mathrm{I} 1=\leq 25, \mathrm{I} 2=>25$ and $\leq 50, \mathrm{I} 3=>50$ and $\leq 75$, and I $4=>75$ ). EEG trials belonging to each category were averaged together, thus yielding four average waveforms for each subject and stimulated hand. Finally, peak amplitudes of A $\delta$-N1 and C-N1 waves of each of the four categories were measured from the average waveforms (Cc-Fz) of each subject. $\mathrm{A} \delta$-N1 and $\mathrm{C}-\mathrm{N} 1$ amplitudes were compared statistically using a two-way repeated-measures ANOVA, with stimulation site (two levels: LH and RH) and pain intensity (four levels: I1-I4) as withinsubject factors. When significant, post hoc comparisons were performed using paired-samples $t$ tests.

Because $\mathrm{A} \delta$-N 1 and $\mathrm{C}-\mathrm{N} 1$ waves overlap spatially and temporally with the subsequent N2-P2 complex, the signal-to-noise ratio of $\mathrm{A} \delta$-N 1 and $\mathrm{C}-\mathrm{N} 1$ activities can be largely enhanced if the contamination of the N2-P2 complex is removed from the LEP responses (Hu et al., 2010). The removal of N2-P2 related activities can be achieved by performing an additional ICA and removing N2 and P2-related ICs, which are easily identified because of the high signal-to-noise ratio of the N2-P2 complex (Mouraux and Iannetti, 2008). Therefore, to isolate $\mathrm{A} \delta$-N1 and $\mathrm{C}-\mathrm{N} 1$ activities, LEP responses were decomposed into a series of ICs, each having a maximally independent time course and a fixed scalp topography. N2- and P2-related ICs were identified and removed, thus generating a new set of EEG data devoid of ICs representing N2-P2 related activities. As described in Hu et al. (2010), ICs were classified as "N2-P2 related" only if they satisfied the following three criteria: (1) reflecting neural activity elicited by the laser stimulus (this was tested by normalizing the time course of the power of each IC as the SD from the mean of the prestimulus interval, $-1000-0 \mathrm{~ms}$, expressed as $Z$ score, and checking if the average $Z$ score within 0 to $+1500 \mathrm{~ms}$ poststimulus interval was larger than 5); (2) having peaks with a latency between 150 and $500 \mathrm{~ms}$ $(\mathrm{A} \delta$-N2/P2) and/or between 700 and $1300 \mathrm{~ms}(\mathrm{C}-\mathrm{N} 2 / \mathrm{P} 2)$; and (3) having a scalp topography centrally distributed and maximal at the vertex. After $\mathrm{A} \delta$-N2/P2- and C-N2/P2-related ICs were removed using this approach, $\mathrm{A} \delta$-N1 and $\mathrm{C}-\mathrm{N} 1$ peaks were detected using the bipolar montage $\mathrm{Cc}-\mathrm{Fz}$, and their scalp topographies were plotted at the respective peak latencies.

\section{Experiment 2: Human EEG during foot stimulation}

Subjects. EEG data were collected from a different group of 95 healthy new subjects ( 50 females) aged $21.6 \pm 1.7$ years ( mean $\pm \mathrm{SD}$, range $=$ $18-25$ years). All subjects gave their written informed consent and were paid for their participation. The local ethics committee approved the experimental procedures.

Nociceptive stimulation and experimental design. Nociceptive stimulation and experimental design were identical to Experiment 1, with the exception that laser stimuli were delivered on the dorsum of the left and 


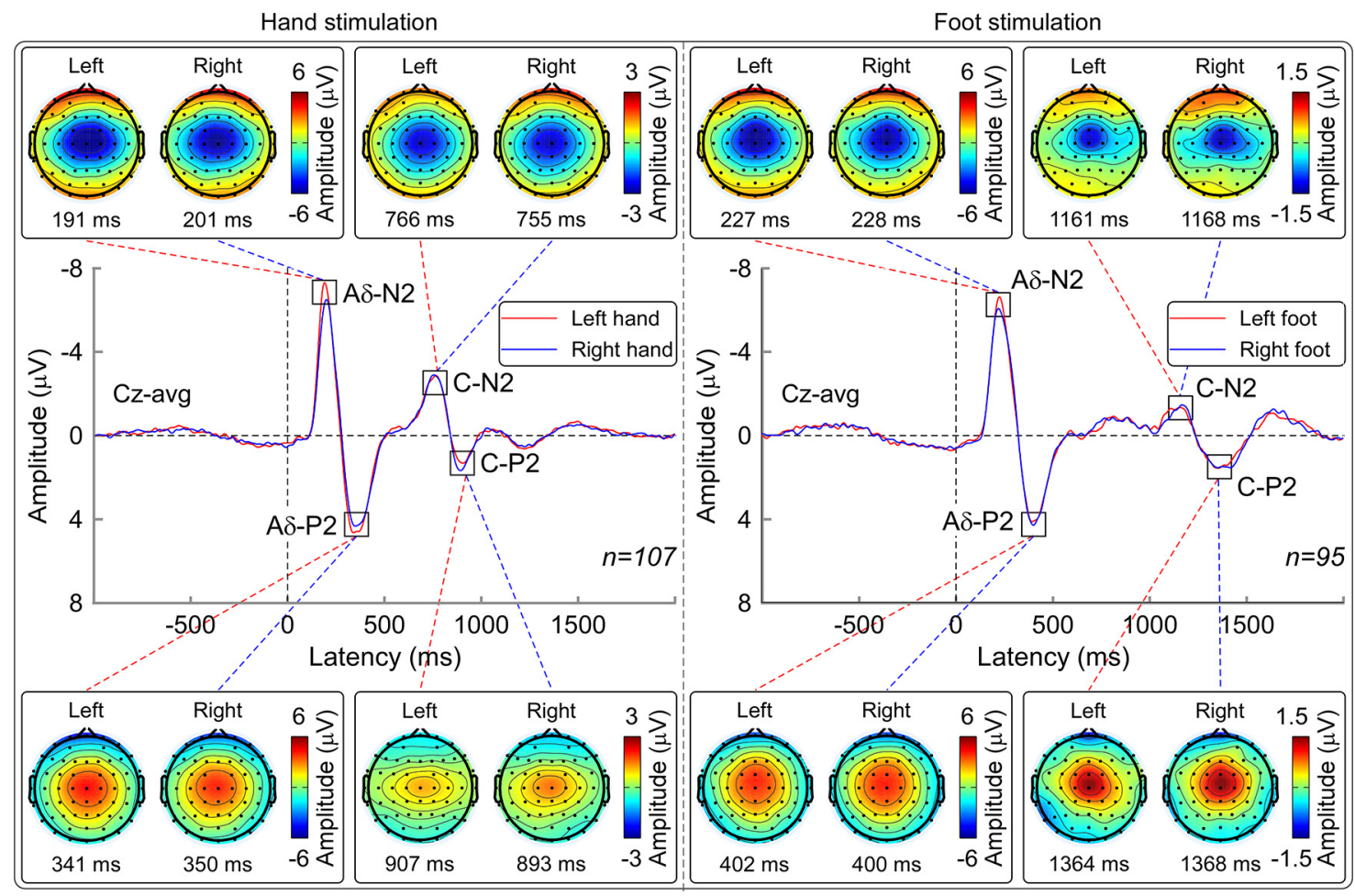

Figure 1. Grand average LEP waveforms and scalp topographies of $A \delta-N 2, A \delta-P 2, C-N 2$, and C-P2 waves. LEP responses were elicited by hand stimulation (left) and foot stimulation (right), on the left side (red waveforms) and right side (blue waveforms). Data were collected from 64 electrodes in 107 subjects (hand stimulation) and 95 subjects (foot stimulation). Displayed signals were recorded from the vertex (Cz vs average reference). Scalp topographies are displayed at the peak latency of $\mathrm{A} \delta-\mathrm{N} 2, \mathrm{~A} \delta-\mathrm{P} 2$, C-N2, and C-P2 waves.

right foot, and that stimulation energies were as follows: E1: $2.5 \mathrm{~J}$; E2: $3 \mathrm{~J}$; E3: $3.5 \mathrm{~J}$; and E4: $4 \mathrm{~J}$.

EEG recording and data analysis. EEG recording and data analysis were identical to Experiment 1 with two exceptions due to the fact that nociceptive stimuli were delivered to the foot. First, the C-N2 and C-P2 were defined as the most negative and positive deflections between 1000 and 1700 ms after stimulus onset. Second, it was not possible to measure N1 amplitude, which is notoriously difficult to isolate after foot stimulation because of the spatial and temporal overlap with the N2 wave.

Experiment 3: Rat ECoG during stimulation of the four paws Subjects. The experiment was conducted on 12 adult male Sprague Dawley rats weighing 300-400 g (Xia et al., 2016). Rats were fed ad libitum with water and food and were housed in separate cages under temperatureand humidity-controlled conditions. They were kept in a $12 \mathrm{~h}$ day/night cycle (lights on from 08:00-20:00). All experimental procedures adhered to the guidelines for animal experimentation.

Nociceptive stimulation and experimental design. Surgical procedures and electrode coordinates have been described previously (Hu et al., 2015). After surgery, rats were kept in their cages for at least $7 \mathrm{~d}$ before the collection of ECoG data. During the ECoG data collection, rats were placed into a plastic chamber (length $\times$ width $\times$ height: $30 \times 30 \times 40$ $\mathrm{cm}^{3}$ ), within which they could move freely. The same Nd:YAP laser stimuli used in human experiments were delivered on the rats' paws through holes ( $5 \mathrm{~mm}$ diameter) on the floor of the chamber when the animal was spontaneously still. Ten laser pulses were delivered to each of the four stimulation sites (left forepaw, right forepaw, left hindpaw, and right hindpaw) using five stimulus energies (E1'-E5' from 1-4 J in steps of $0.75 \mathrm{~J}$ ) for a total of 200 pulses. The order of stimulation sites and stimulus energies was pseudorandomized, the interstimulus interval was never $<30 \mathrm{~s}$, and the laser target was changed after each stimulus to avoid nociceptor fatigue or sensitization. Animals were video-recorded throughout the experiment and pain-related behaviors elicited by the laser stimuli were quantified using a validated $0-4$ scale where 0 is immobility; 1 is head turning, including shaking or elevating the head; 2 is flinching; 3 is withdrawal involving paw retraction from the nociceptive stimulus; and
Table 1. Latency and amplitude of LEP waves elicited by left and RH stimulation

\begin{tabular}{llllll}
\hline & \multicolumn{2}{l}{ LH stimulation (mean \pm SEM) } & & \multicolumn{2}{l}{ RHstimulation (mean \pm SEM) } \\
\cline { 2 - 3 } \cline { 5 - 6 } & Latency $(\mathrm{ms})$ & Amplitude $(\mu \mathrm{V})$ & & Latency $(\mathrm{ms})$ & Amplitude $(\mu \mathrm{V})$ \\
\hline A $\delta$-N1 & $167 \pm 3$ & $-5.2 \pm 0.3$ & & $173 \pm 2$ & $-4.3 \pm 0.3$ \\
$\mathrm{~A} \delta$-N2 & $202 \pm 2$ & $-8.6 \pm 0.4$ & & $206 \pm 3$ & $-7.8 \pm 0.3$ \\
$\mathrm{~A} \delta$-P2 & $355 \pm 4$ & $6.1 \pm 0.3$ & & $364 \pm 4$ & $5.7 \pm 0.3$ \\
$\mathrm{C}-\mathrm{N} 1$ & $736 \pm 6$ & $-3 \pm 0.2$ & & $737 \pm 6$ & $-2.8 \pm 0.2$ \\
$\mathrm{C}-\mathrm{N} 2$ & $762 \pm 5$ & $-4.8 \pm 0.2$ & & $765 \pm 5$ & $-4.9 \pm 0.2$ \\
$\mathrm{C}-\mathrm{P} 2$ & $886 \pm 5$ & $2.7 \pm 0.2$ & & $890 \pm 5$ & $2.3 \pm 0.2$ \\
\hline
\end{tabular}

$\mathrm{A} \delta$-N2, $\mathrm{A} \delta-\mathrm{P} 2, \mathrm{C}-\mathrm{N} 2$, and $\mathrm{C}-\mathrm{P} 2$ waves were measured at $\mathrm{C} z$-average.

$\mathrm{A} \delta$ - $\mathrm{N} 1$ and $\mathrm{C}-\mathrm{N} 1$ waves were measured at $\mathrm{C}-\mathrm{F} \mathrm{F}$.

4 is licking the stimulated body territory and whole-body movement (Fan et al., 1995, 2009). White noise was played throughout the experiment to avoid the activation of the auditory system by laser-generated ultrasounds and thereby uniquely record the cortical responses related to the activation of the nociceptive system (Xia et al., 2016).

ECoG recording and data analysis. ECoG recording and analysis were virtually identical to Experiment 1 . To explore the spatial differences between the response elicited by the stimulation of the left and right paws, we plotted the scalp topographies of the earliest part of C-LEPs (i.e., from $110-130 \mathrm{~ms}$ for forepaw stimulation and from $210-230 \mathrm{~ms}$ for hindpaw stimulation, corresponding to the C-N1) in steps of $10 \mathrm{~ms}$. To test whether these earliest responses were lateralized with respect to the stimulated paw, we compared single-subject LEP waveforms elicited by the stimulation of the left and right paws using the same procedure of Experiments 1 and 2.

To minimize the influence of widespread activities and enhance spatially discrete activities like the $\mathrm{C}-\mathrm{N} 1$ wave, we average referenced the data (Xia et al., 2016). We measured the peak latency and amplitude of the C-N1 waves in single-subject LEP waveforms averaged across trials and stimulus energies. Importantly, there was a clearly detectable C-N1 response in all animals. The C-N1 wave was optimally detected from electrode RFR (after left forepaw stimulation), LFL (after right fore- 

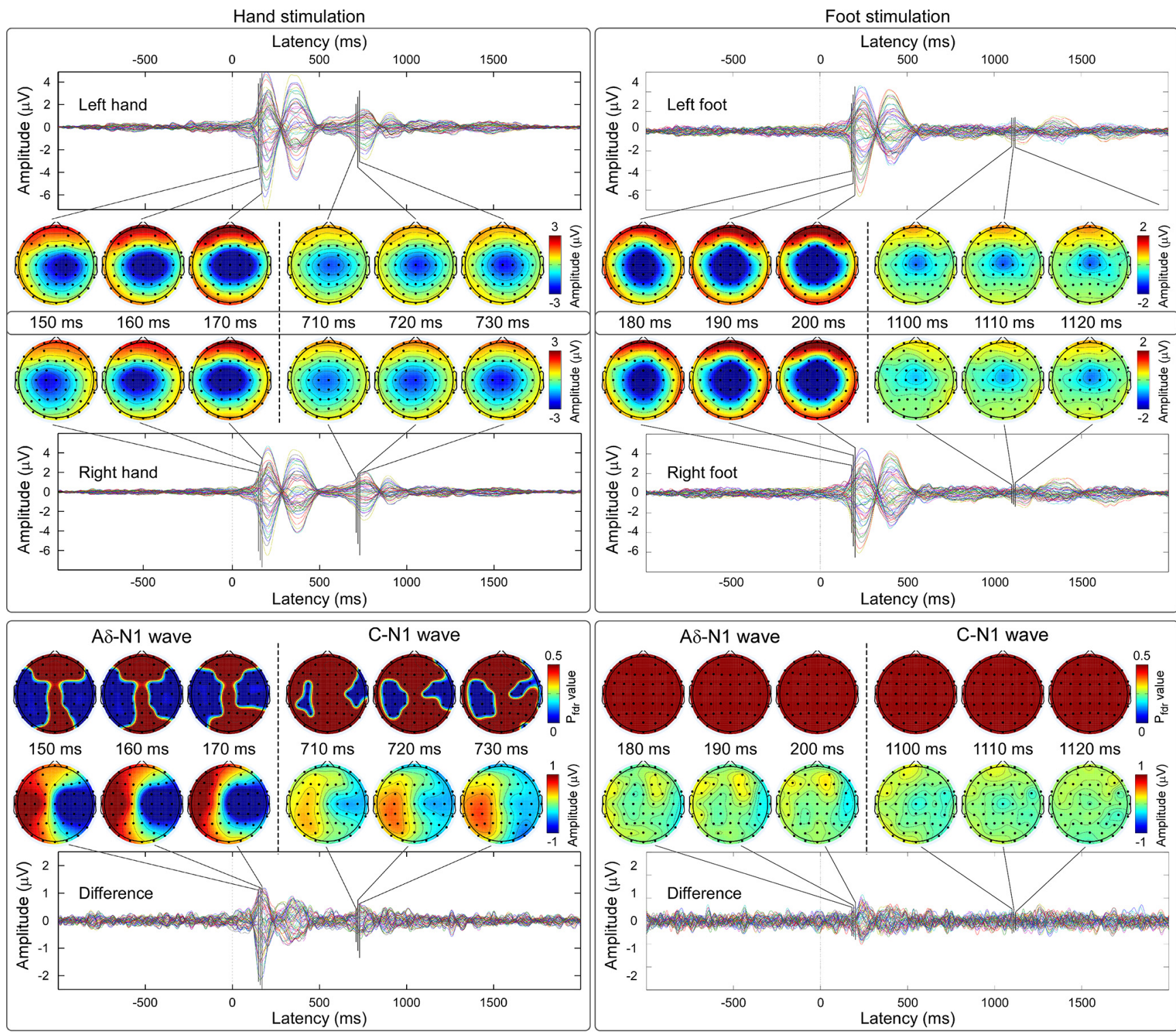

Figure 2. Topographies and statistical comparisons of the earliest part of $A \delta$ - and C-LEPs elicited by left and right stimulation of hand and foot. Top, Grand averages from all electrodes are plotted in different colors and superimposed. Series of scalp topographies of the earliest part of A $\delta$-LEPs and C-LEPs (A $\delta$-LEP: $150-170 \mathrm{~ms}$, hand; 180 -200 ms, foot; C-LEP: $710-730$ $\mathrm{ms}$, hand; $1100-1120 \mathrm{~ms}$, foot) are displayed at 10-ms intervals. Note that the scalp topographies of the earliest part of the A $\delta$-LEPs and C-LEPs elicited by hand stimulation show a negativity contralateral to the stimulated side, whereas the scalp topographies of the earliest part of the A $\delta$-LEPs and C-LEPs elicited by foot stimulation are centrally distributed. This observation is compatible with the somatotopical organization of the primary somatosensory cortex. Bottom, Grand averages and scalp topographies of the difference waveforms obtained by subtracting the LEPs elicited by right and left stimulation for hand (left) and foot (right). The top row shows the scalp topography of the statistical comparisons between left and right LEPs at the $A \delta$-N 1 and C-N 1 latencies. The earliest part of both A $\delta$-LEPs and C-LEPs elicited by hand stimulation shows significant differences $\left(p_{\text {FDR }}<0.05\right)$ localized bilaterally on the electrodes overlying the hand area in the primary somatosensory cortices. In contrast, the earliest part of both A $\delta$-LEPs and C-LEPs elicited by the stimulation of the left and right foot was not significantly different.

paw stimulation), PR1 (after left hindpaw stimulation), and PL1 (after right hindpaw stimulation). Single-subject rereferenced waveforms were subsequently averaged to obtain group-level waveforms. Group-level scalp topographies at the peak latency of the C-N1 wave were computed by spline interpolation.

Statistical analysis. To assess the dependence of C-N1 amplitudes on stimulus energy, we first calculated the average LEP waveform for each level of stimulus energy, thus yielding five average waveforms (E1'-E5') for each of the four stimulation sites. Peak amplitude of the C-N1 wave at each stimulus energy was measured in each subject. C-N1 amplitudes were compared using a two-way repeated-measures ANOVA, with stimulation site (four levels: left and right forepaw and hindpaw) and stimulus energy (five levels: E1'-E5') as within-subject factors. When significant, post hoc pairwise comparisons were performed using paired-samples $t$ tests.

\section{Results}

\section{Experiments 1 and 2: Human EEG}

Waveforms and topographies of the early part of human C-LEPs Figure 1 shows the grand average human LEP waveforms at $\mathrm{Cz}$ and the scalp topographies at the peak latencies of $\mathrm{A} \delta-\mathrm{N} 2, \mathrm{~A} \delta-\mathrm{P} 2$, C-N2, and C-P2 waves for both hand and foot stimulation. Regardless of where the stimulus was delivered, $\mathrm{A} \delta$-N2 and C-N2 waves were always maximal at the vertex and extended bilaterally toward the temporal regions, whereas $\mathrm{A} \delta$-P2 and C-P2 waves were more centrally distributed (Fig. 1), as also described in previous studies (Kunde and Treede, 1993; Mouraux and Iannetti, 2009; Hu et al., 2014b). Group-level latencies and amplitudes of 

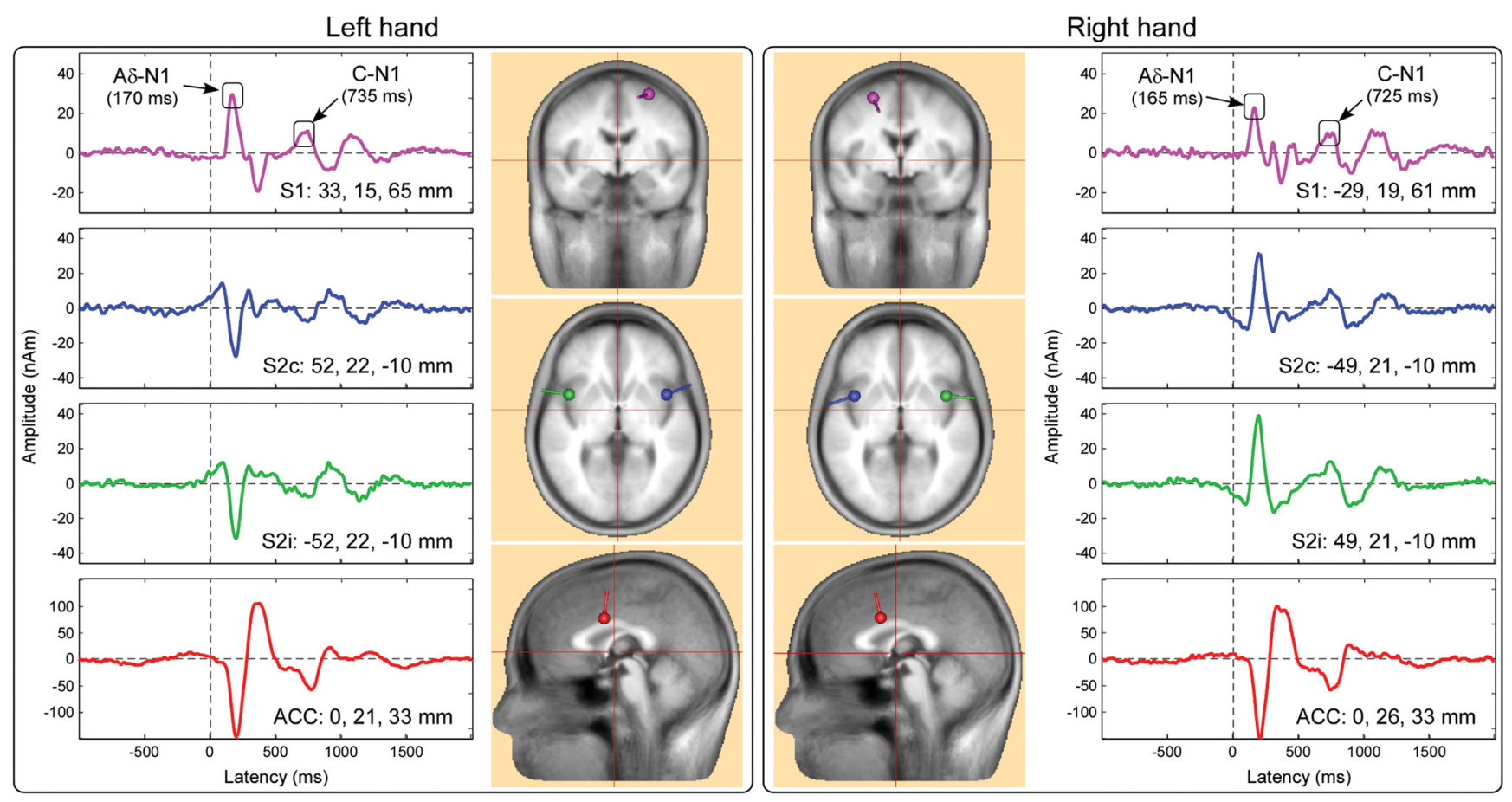

Left foot
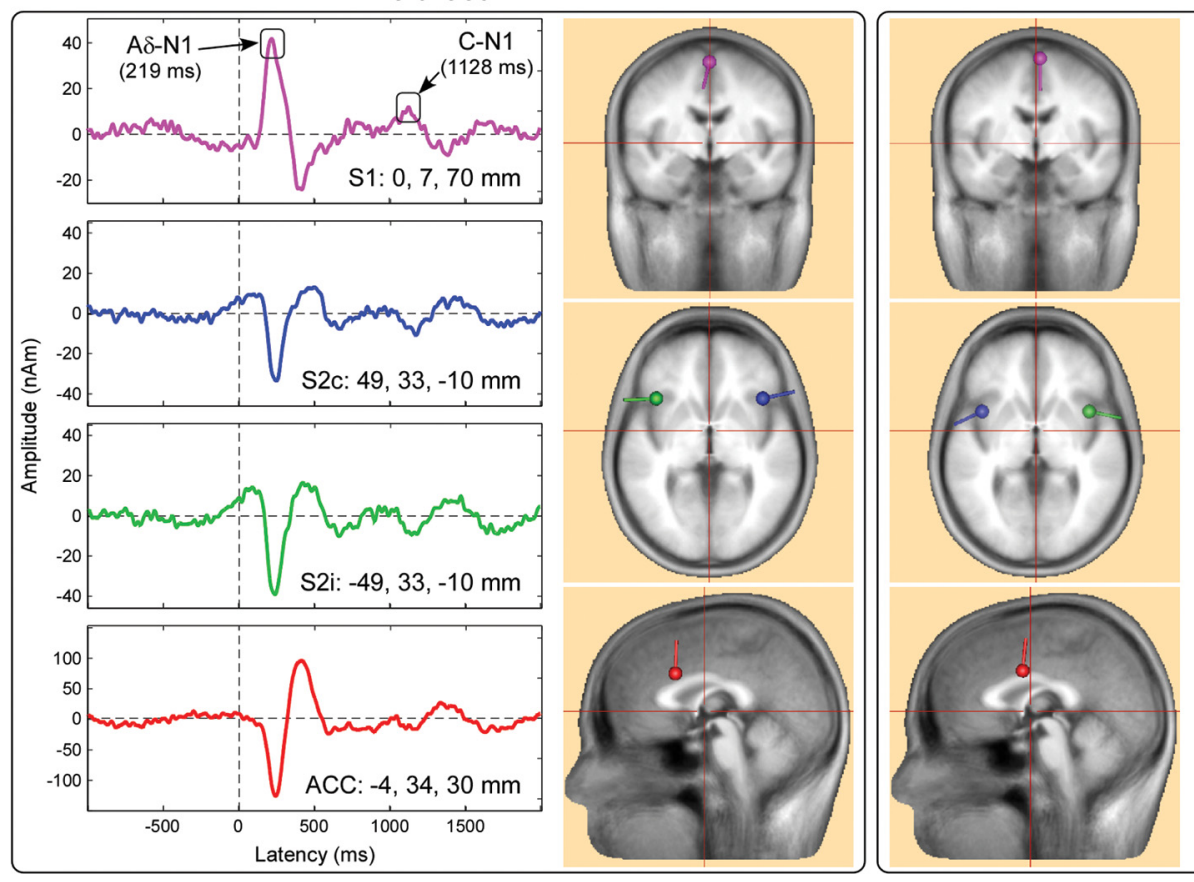

Right foot
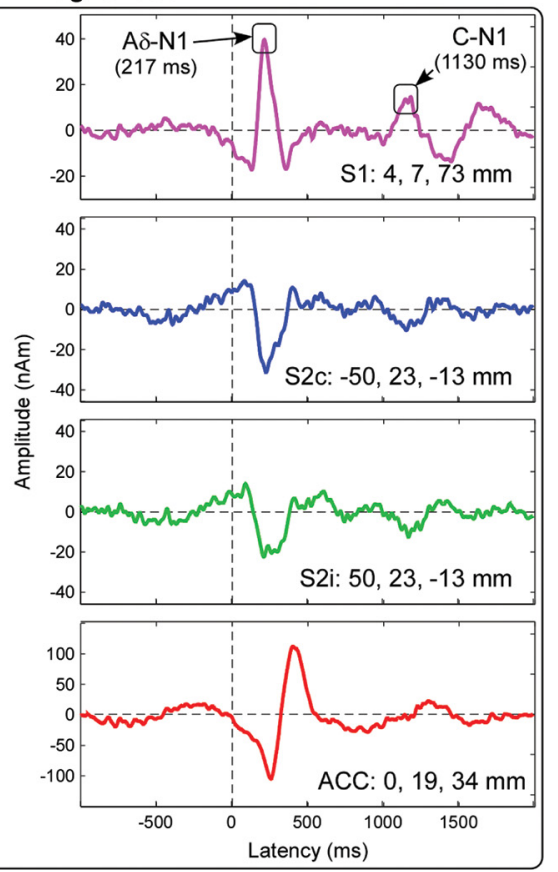

Figure 3. Dipolar sources of group average scalp LEP waveforms elicited by hand (top) and foot (bottom) stimulation. LEP responses were explained by four equivalent dipoles, located in the S1 (pink), the bilateral S2 (green and blue), and the ACC ( red). Source time courses are displayed in the lateral part of each panel. Note that the spatial locations of $\$ 2$ and ACC dipoles are similar regardless of stimulated side. In contrast, the spatial location of the $\$ 1$ dipole varies according to the stimulated side, but only when stimuli are delivered to the hand (top): it was located in the right $\mathrm{S} 1$ when the $\mathrm{LH}$ was stimulated and vice versa. Note also that the peaks of the $\mathrm{S} 1$ source time course occur at the latency of the A $\delta$-N1 and C-N1 waves.

the main peaks of both the A $\delta$-LEPs and C-LEPs are reported in Table 1.

The top panels of Figure 2 shows the same grand average LEP waveforms, but from all recorded electrodes, in response to hand (left) and foot (right) stimulation. After hand stimulation, the scalp topographies of the earliest activity of both the A $\delta$-LEPs (150-170 ms) and the C-LEPs (710-730 ms) displayed a clear negative maximum on the central electrodes overlying the hemisphere contralateral to the stimulation side. In contrast, after foot stimulation, the scalp topographies of the earliest activity in both A $\delta$-LEPs (180-200 ms) and C-LEPs (1100-1120 ms) were centrally distributed. The bottom panels of Figure 2 show the grand average of the difference between LEP waveforms elicited by the stimulation of the left and right side, as well as series of scalp topographies in the earliest part of both A $\delta$-LEPs and C-LEPs (A $\delta$-LEP: 150-170 ms, hand; 180-200 ms, foot; C-LEP: 710-730 $\mathrm{ms}$, hand; $1100-1120 \mathrm{~ms}$, foot). In these time intervals, A $\delta$-LEPs and C-LEPs were significantly different when elicited by left and 
N1 response before the removal of N2-P2 ICs

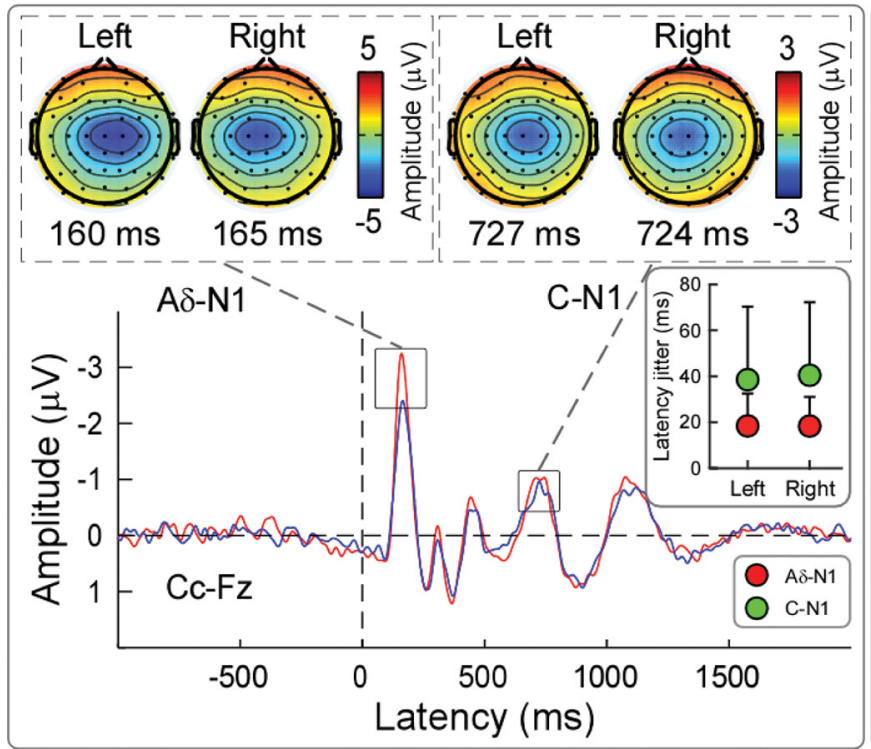

N1 response after the removal of N2-P2 ICs
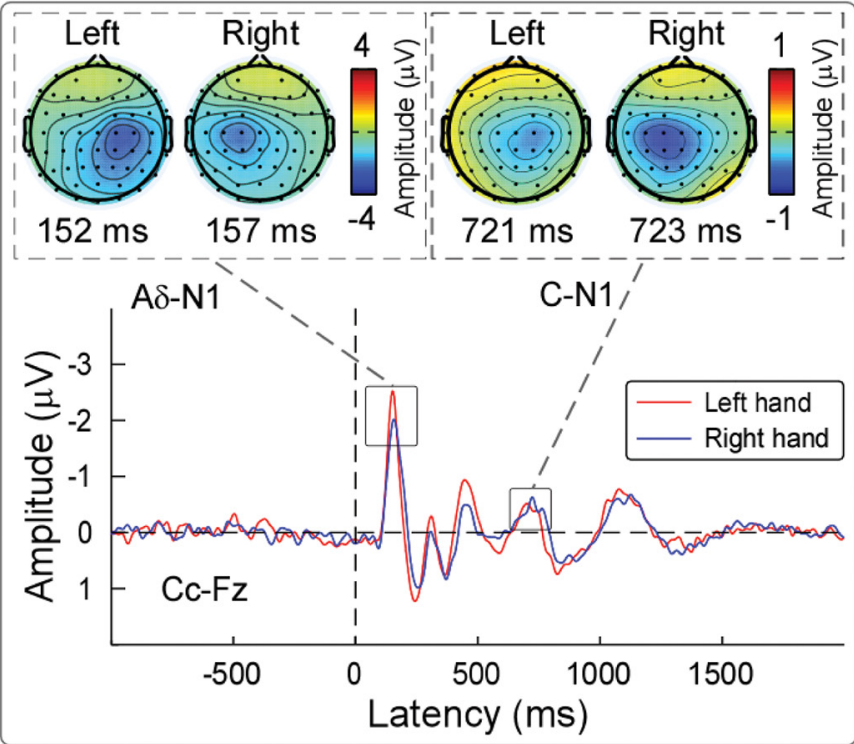

Figure 4. Detection of $\mathrm{A} \delta$-N1 and (-N1 waves. Grand averages and scalp topographies of A $\delta$-N1 and C-N1 waves elicited by stimulating the hand dorsum on the left side (red waveforms) and the right side (blue waveforms). Left, A $\delta$ - $\mathrm{N} 1$ and $\mathrm{C}-\mathrm{N} 1$ waves are measured from the contralateral central electrode (Cc vs $\mathrm{Fz}$ ), a montage that allows the isolation of A $\delta$-N1 and C-N1 peaks. The A $\delta$-N1 and C-N1 scalp topographies have a maximum contralateral to the stimulated side. Histograms in the inset show the absolute difference (mean \pm SD) between single-subject and group-average latency of $\mathrm{A} \delta$-N1 and C-N1 waves: the C-N1 wave has a larger jitter than the $A \delta$-N1 wave. Right, After the removal of the independent components capturing the activity of the partially overlapping $\mathrm{N} 2-\mathrm{P} 2$ vertex waves, the topographies of both the $\mathrm{A} \delta$-N1 and $\mathrm{C}-\mathrm{N} 1$ are more lateralized.

right hand stimulation $\left(p_{\mathrm{FDR}}<0.05\right)$, but not different when elicited by left and right foot stimulation. The differences observed after hand stimulation occurred at the latencies of the $\mathrm{A} \delta$-N1 and of the C-N1 waves, and were localized bilaterally on the electrodes overlying the hand area in the S1 (Fig. 2).

\section{Source analysis of the C-N1 waves elicited by hand and foot stimulation}

Time courses and locations of the dipolar sources of LEPs are shown in Figure 3. The source explaining the time window of the $\mathrm{A} \delta$ - $\mathrm{N} 1$ and $\mathrm{C}-\mathrm{N} 1$ waves was located in the contralateral S1, whereas the sources explaining the time window of the $\mathrm{A} \delta-\mathrm{N} 2 / \mathrm{P} 2$ and $\mathrm{C}-\mathrm{N} 2 / \mathrm{P} 2$ complex were located in the bilateral operculo-insular cortices (S2 and/or insula) and in the anterior cingulate cortex (ACC). Although the location of bilateral S2/insula and ACC were almost identical regardless of stimulated site (hand or foot) or stimulated side (right or left), the generator of the N1 elicited by hand stimulation was always contralateral to the stimulated side (Fig. 3, top): in the right $\mathrm{S} 1$ when the LH was stimulated, and in the left $\mathrm{S} 1$ when the RH was stimulated. Importantly, this was not the case when considering the earliest part of the $\mathrm{A} \delta$ - and C-LEPs elicited by foot stimulation (Fig. 3, bottom): regardless of whether the right or the left foot was stimulated, the S1 generator was always located on the midline in the foot area of the S1. At all stimulated sites, the time course of the S1 source activity clearly showed both $\mathrm{A} \delta$-N1 and $\mathrm{C}-\mathrm{N} 1$ waves. The residual variance within the $\mathrm{A} \delta$-N1 time window (150-170 ms, hand; $180-200 \mathrm{~ms}$, foot) was $2.8 \%$ and $1.4 \%$ for $\mathrm{LH}$ and RH stimulation, and 3.1\% and $6.1 \%$ for left and right foot stimulation. The residual variance within the C-N1 time window (710-730 ms, hand; 1110-1130 $\mathrm{ms}$, foot) was $3.9 \%$ and $2.3 \%$ for $\mathrm{LH}$ and $\mathrm{RH}$ stimulation, and $9.3 \%$ and $5.1 \%$ for left and right foot stimulation. These results indicate that dipoles in S1 explained satisfactorily the scalp topography of both the $\mathrm{A} \delta$-N1 and the C-N1 peaks.
Isolation of the C-N1 wave elicited by hand stimulation

The left panel of Figure 4 shows the grand average LEP waveforms elicited by the stimulation of $\mathrm{LH}$ and $\mathrm{RH}$ at electrode $\mathrm{Cc}$ referenced to Fz. Using this Cc-Fz montage, both the $\mathrm{A} \delta$-N1 and C-N1 waves could be clearly detected. A $\delta$-N1 and C-N1 scalp topographies showed a maximum over the central electrodes contralateral to the stimulated side. Across subjects, latencies and amplitudes of $\mathrm{A} \delta$-N1 and C-N1 waves were as follows: (1) A $\delta$-N1: $167 \pm 3 \mathrm{~ms}$ and $-5.2 \pm 0.3 \mu \mathrm{V}$ (LH stimulation; mean $\pm \mathrm{SEM}$ ); $173 \pm 2 \mathrm{~ms}$ and $-4.3 \pm 0.3 \mu \mathrm{V}$ (RH stimulation); and (2) C-N1: $736 \pm 6 \mathrm{~ms}$ and $-3 \pm 0.2 \mu \mathrm{V}$ (LH stimulation); $737 \pm 6 \mathrm{~ms}$ and $-2.8 \pm 0.2 \mu \mathrm{V}$ (RH stimulation). The between-subject latency variability of the $\mathrm{A} \delta$-N1 was $18 \pm 2 \mathrm{~ms}$ (LH stimulation) and $19 \pm 2 \mathrm{~ms}$ ( $\mathrm{RH}$ stimulation). The between-subject latency variability of the C-N1 was $37 \pm 4 \mathrm{~ms}$ (LH stimulation) and $40 \pm 4 \mathrm{~ms}$ (RH stimulation). Two-way repeated-measures ANOVA conducted using the afferent pathway (two levels: $\mathrm{A} \delta$ and C) and the stimulated side (two levels: left and right) revealed a significant main effect of afferent pathway $\left(F_{(1,70)}=27.4, p<0.001, \eta_{\mathrm{p}}^{2}=0.28\right)$, indicating that the latency jitter was significantly larger for $\mathrm{C}-\mathrm{N} 1$ than $\mathrm{A} \delta$-N1 wave.

The right panel of Figure 4 shows the grand average LEP waveforms (Cc-Fz) after the removal of the N2-P2 complex using an additional ICA. The scalp topographies of both $\mathrm{A} \delta$-N 1 and $\mathrm{C}-\mathrm{N} 1$ waves show that the negative maximum over the central electrodes contralateral to the stimulated side is more clearly isolated compared with the LEP waveforms before N2-P2 removal.

\section{Relationship between C-N1 and other $A \delta$ - and C-LEP waves}

Results of correlation analysis between latency/amplitude of each C-LEP wave and latency/amplitude of the other A $\delta$-LEP and C-LEP waves are summarized in Figure 5 and Table 2. Some of these results are helpful in understanding the functional significance of C-LEPs in general and of the C-N1 wave in particular. 


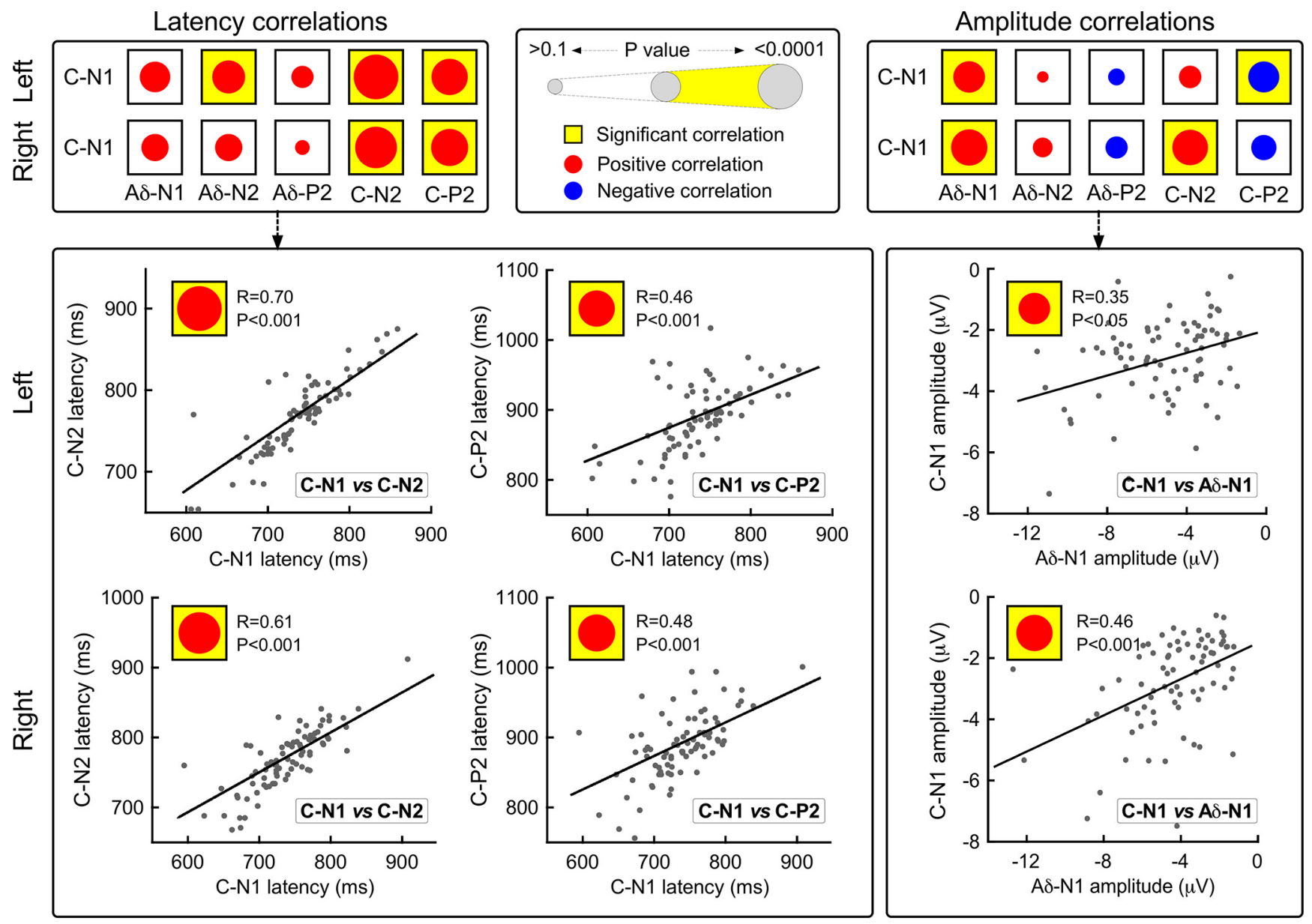

Figure 5. Correlations between C-N1 and other LEP waves. Top, All possible latency and amplitude correlations between the C-N1 and other LEP waves (i.e., A $\delta$-N1, A $\delta$-N2, A $\delta$-P2, C-N2, and (-P2). Red and blue dots represent positive and negative correlations and the dot size reflects the significance of the correlation. When a correlation was significant, the corresponding box was marked in yellow. Note that, for both LH and RH dorsum stimulations, C-N1 amplitudes were most strongly correlated with A $\delta$-N1 amplitudes. Bottom, Single-subject data for the significant correlations. Each dot represents a subject and black lines represent the best linear fit.

Table 2. Latency and amplitude correlations between LEP waves

\begin{tabular}{|c|c|c|c|c|c|c|c|c|c|c|c|c|c|}
\hline & & \multicolumn{6}{|c|}{ Latency correlations ( $R$ values) } & \multicolumn{6}{|c|}{ Amplitude correlations ( $R$ values) } \\
\hline & & $\mathrm{A} \delta-\mathrm{N} 1$ & $\mathrm{~A} \delta$ - $\mathrm{N} 2$ & $\mathrm{~A} \delta-\mathrm{P} 2$ & C-N1 & C-N2 & $C-P 2$ & $\mathrm{~A} \delta$-N1 & $\mathrm{A} \delta-\mathrm{N} 2$ & $\mathrm{~A} \delta-\mathrm{P} 2$ & C-N1 & C-N2 & $C-P 2$ \\
\hline \multirow[t]{2}{*}{ C-N1 } & Left & 0.33 & $0.38^{*}$ & 0.18 & - & $0.70^{*}$ & $0.46^{*}$ & $0.35^{*}$ & 0.05 & -0.10 & - & 0.18 & $-0.34^{*}$ \\
\hline & Right & 0.26 & 0.26 & 0.08 & - & $0.61^{*}$ & $0.48^{*}$ & $0.46^{*}$ & 0.14 & -0.17 & - & $0.44^{*}$ & -0.22 \\
\hline \multirow[t]{2}{*}{ C-N2 } & Left & 0.20 & 0.15 & 0.11 & $0.70^{*}$ & - & $0.76^{*}$ & 0.13 & $0.56^{*}$ & $-0.43^{*}$ & 0.18 & - & $-0.49^{*}$ \\
\hline & Right & 0.14 & 0.13 & 0.07 & $0.61^{*}$ & - & $0.76^{*}$ & 0.26 & $0.56^{*}$ & $-0.56^{*}$ & $0.44^{*}$ & - & $-0.69^{*}$ \\
\hline \multirow[t]{2}{*}{ C-P2 } & Left & 0.14 & 0.04 & 0.17 & $0.46^{*}$ & $0.76^{*}$ & - & 0.14 & 0.00 & 0.12 & $-0.34^{*}$ & $-0.49^{*}$ & - \\
\hline & Right & 0.18 & 0.14 & 0.07 & $0.48^{*}$ & $0.76^{*}$ & - & -0.12 & $-0.32^{*}$ & $0.42^{*}$ & -0.22 & $-0.69^{*}$ & - \\
\hline
\end{tabular}

Significant correlations for both $\mathrm{LH}$ and RH stimulations are shown in bold.

${ }^{*} p_{\text {fdr }}<0.05$.

First, the latencies of the different C-LEP waves (C-N1, C-N2, and $\mathrm{C}-\mathrm{P} 2$ ) were strongly correlated among themselves, whereas they were not correlated with those of A $\delta$-LEP waves $(\mathrm{A} \delta$-N1, $\mathrm{A} \delta$-N2, and $\mathrm{A} \delta$-P2) (Table 2). This finding confirms that $\mathrm{A} \delta$ LEPs and C-LEPs are consequent to the arrival of somatosensory volleys relayed by different populations of myelinated and unmyelinated peripheral afferents.

Second, the amplitude of the C-N1 wave from both hands was significantly and positively correlated with that of the $\mathrm{A} \delta$ - $\mathrm{N} 1$ wave, whereas it was not consistently correlated with the amplitude of the other vertex waves: that is, C-N2, C-P2, A $\delta$-N2, and $\mathrm{A} \delta$-P2 ( $R$ values and significance are reported in Table 2$)$. In contrast, amplitude of the vertex $\mathrm{C}-\mathrm{N} 2$ was significantly correlated with amplitudes of the vertex $\mathrm{A} \delta$ - $\mathrm{N} 2, \mathrm{~A} \delta$-P2, and C-P2, but not with the amplitude of either the $\mathrm{A} \delta$-N1 or the $\mathrm{C}-\mathrm{N} 1$ wave ( $R$ values and significance are reported in Table 2). This finding provides further evidence that the $\mathrm{N} 1$ waves elicited by both $\mathrm{A} \delta$ and $\mathrm{C}$ afferent volleys are generated by cortical structures different from those generating the vertex waves $(\mathrm{A} \delta$-N2/P2 and C-N2/P2).

Dependence of human C-N1 amplitudes on stimulus energy and pain intensity

Amplitudes of the main A $\delta$-LEP and C-LEP waves for different stimulus energies (E1-E4) and hand stimulation sites ( $\mathrm{LH}$ and $\mathrm{RH}$ ), together with their statistical comparison, are summarized in Table 3. Two-way repeated-measures ANOVA with factors 
Table 3. Effect of laser energy (E1-E4) and stimulation site (LH and RH) on LEP amplitudes

\begin{tabular}{|c|c|c|c|c|c|c|c|c|c|c|c|}
\hline & \multicolumn{4}{|c|}{ LH stimulation (mean \pm SEM) } & \multicolumn{4}{|c|}{ RH stimulation (mean \pm SEM) } & \multicolumn{3}{|l|}{ Two-way ANOVA } \\
\hline & E1 & E2 & E3 & E4 & E1 & E2 & E3 & E4 & Energy & Site & Interaction \\
\hline Pain intensity $(0-10)$ & $3.4 \pm 0.1$ & $4.2 \pm 0.1$ & $5.7 \pm 0.1$ & $7.6 \pm 0.1$ & $3.3 \pm 0.1$ & $4.1 \pm 0.1$ & $5.5 \pm 0.2$ & $7.4 \pm 0.2$ & $F=726.5^{* * *}$ & $F=5.7^{*}$ & $F=0.5$ \\
\hline $\mathrm{A} \delta-\mathrm{N} 1$ & $-0.3 \pm 0.2$ & $-0.9 \pm 0.3$ & $-5.3 \pm 0.5$ & $-11.2 \pm 0.5$ & $-0.1 \pm 0.2$ & $-1.2 \pm 0.3$ & $-4.0 \pm 0.4$ & $-9.5 \pm 0.6$ & $F=243.9^{* * *}$ & $F=7.3^{* *}$ & $F=3.4^{*}$ \\
\hline $\mathrm{A} \delta$ - $\mathrm{N} 2$ & $0.1 \pm 0.3$ & $-2.9 \pm 0.6$ & $-15.5 \pm 1.3$ & $-33.4 \pm 1.4$ & $-0.2 \pm 0.4$ & $-2.3 \pm 0.5$ & $-13.1 \pm 1.1$ & $-32.5 \pm 1.4$ & $F=370.8^{* * *}$ & $F=3.8$ & $F=1.6$ \\
\hline$A \delta-P 2$ & $0.8 \pm 0.4$ & $3.0 \pm 0.7$ & $13.3 \pm 1.0$ & $26.1 \pm 1.2$ & $-0.1 \pm 0.5$ & $2.8 \pm 0.6$ & $12.2 \pm 1.0$ & $25.9 \pm 1.2$ & $F=300.7^{* * *}$ & $F=1.9$ & $F=0.3$ \\
\hline C-N1 & $-2.3 \pm 0.3$ & $-3.1 \pm 0.2$ & $-3.3 \pm 0.2$ & $-2.5 \pm 0.2$ & $-2.4 \pm 0.3$ & $-2.7 \pm 0.3$ & $-3.0 \pm 0.3$ & $-2.4 \pm 0.2$ & $F=3.6^{*}$ & $F=2.0$ & $F=0.4$ \\
\hline C-N2 & $-6.4 \pm 0.6$ & $-9.3 \pm 0.6$ & $-8.5 \pm 0.5$ & $-6.2 \pm 0.6$ & $-6.4 \pm 0.7$ & $-9.3 \pm 0.7$ & $-8.5 \pm 0.5$ & $-7.7 \pm 0.5$ & $F=9.6^{* * *}$ & $F=1.1$ & $F=1.3$ \\
\hline C-P2 & $6.1 \pm 0.7$ & $7.3 \pm 0.6$ & $4.0 \pm 0.5$ & $2.0 \pm 0.8$ & $6.2 \pm 0.6$ & $7.3 \pm 0.6$ & $5.3 \pm 0.5$ & $1.8 \pm 0.5$ & $F=31.5^{* * *}$ & $F=0.6$ & $F=1.0$ \\
\hline
\end{tabular}

$\mathrm{A} \delta$-N2, $\mathrm{A} \delta$-P2, C-N2, and C-P2 amplitudes $(\mu \mathrm{V})$ were measured at Cz-average.

$\mathrm{A} \delta$-N1 and $\mathrm{C}-\mathrm{N} 1$ amplitudes $(\mu \mathrm{V})$ were measured at $\mathrm{C}-\mathrm{Fz}$.

Significant effects are shown in bold.

${ }^{*} p<0.05 ;{ }^{* *} p<0.01$; ${ }^{* * *} p<0.001$.

stimulus energy (four levels: E1-E4) and stimulated side (two levels: left and right) showed that $\mathrm{A} \delta$-N1 amplitudes were significantly modulated by stimulus energy $\left(F_{(3,249)}=243.9, p<0.001\right.$, $\left.\eta_{\mathrm{p}}^{2}=0.86\right)$, stimulated side $\left(F_{(1,83)}=7.26, p=0.009, \eta_{\mathrm{p}}^{2}=0.08\right)$, and their interaction $\left(F_{(3,249)}=3.40, p=0.02, \eta_{\mathrm{p}}^{2}=0.06\right)$, and that amplitudes of the $\mathrm{A} \delta$-N2, A $\delta$-P2, C-N1, C-N2, and C-P2 waves were significantly modulated only by stimulus energy.

Post hoc pairwise comparisons indicated that $\mathrm{A} \delta$ - $\mathrm{N} 1$ amplitudes at E3 and E4 were significantly larger than those at E1 and E2 $(\mathrm{E} 1<\mathrm{E} 3, \mathrm{E} 1<\mathrm{E} 4, \mathrm{E} 2<\mathrm{E} 3, \mathrm{E} 2<\mathrm{E} 4, \mathrm{E} 3<\mathrm{E} 4, p<$ 0.001 for all comparisons) for both stimulated sides, and A $\delta$-N 1 amplitudes at E2 were significantly larger than those at $\mathrm{E} 1(\mathrm{E} 1<\mathrm{E} 2, p<0.01)$ for RH stimulation. In addition, pairwise comparisons showed that $\mathrm{C}-\mathrm{N} 1$ amplitudes were significantly larger at E3 than at E1 and E4 $(\mathrm{E} 3>\mathrm{E} 1, p=0.01$; E3 $>$ $\mathrm{E} 4, p=0.03)$, and at $\mathrm{E} 2$ than at $\mathrm{E} 1(\mathrm{E} 2>\mathrm{E} 1, p=0.03)$ for $\mathrm{LH}$ stimulation and larger at E3 than at E4 $(p=0.03)$ for $\mathrm{RH}$ stimulation. The results of these post hoc comparisons suggest that the higher the stimulus energy, the larger the $\mathrm{A} \delta$-N1 amplitude (Fig. 6, top), whereas C-N1 amplitude is maximal at a moderate level of stimulus energy (i.e., E3; Fig. 6, bottom). Similarly, post hoc pairwise comparisons revealed that the higher the stimulus energy, the larger the amplitudes of $\mathrm{A} \delta$-N2 and $\mathrm{A} \delta$-P2 waves. In contrast, C-N2 and C-P2 amplitudes were maximal at a moderate level of stimulus energy (i.e., E2 or E3), as described previously (Hu et al., 2014b).

Two-way repeated-measures ANOVA with factors pain intensity (four levels: I1-I4) and stimulated side (two levels: left and right) showed that $\mathrm{A} \delta$-N1 amplitudes were significantly modulated by pain intensity $\left(F_{(3,240)}=240.8, p<0.001, \eta_{\mathrm{p}}^{2}=0.72\right)$ and stimulated side $\left(F_{(1,80)}=5.30, p=0.024, \eta_{\mathrm{p}}^{2}=0.06\right)$, while C-N1 amplitudes waves were significantly modulated only by pain intensity $\left(F_{(3,213)}=3.59, p=0.015, \eta_{\mathrm{p}}^{2}=0.05\right)$.

Post hoc pairwise comparisons indicated that $\mathrm{A} \delta$-N1 amplitudes monotonically increased with perceived pain at both stimulation sites (I1 $<$ I $2<\mathrm{I} 3<\mathrm{I} 4, p<0.001$ for all comparisons) and that $\mathrm{C}-\mathrm{N} 1$ amplitudes were significantly larger at I2 and I3 than at I 1 and I4 $(\mathrm{I} 1<\mathrm{I} 2$, I $4<\mathrm{I} 2, \mathrm{I} 1<\mathrm{I} 3, \mathrm{I} 4<\mathrm{I} 3, p<0.05$ for all comparisons) for $\mathrm{RH}$ stimulation.

\section{Experiment 3: Rat ECoG}

Waveforms and topographies of the early part of rat C-LEPs Figure 7 shows the grand average rat C-LEPs after stimulation of the forepaw and hindpaw on the right and left sides. Scalp topographies of the earliest activity in the response evoked by right and left forepaw stimulation (110-130 ms; Fig. 7, left) displayed a clear negative maximum on the hemisphere contralateral to the stimulated side. Scalp topographies of the earliest part of the

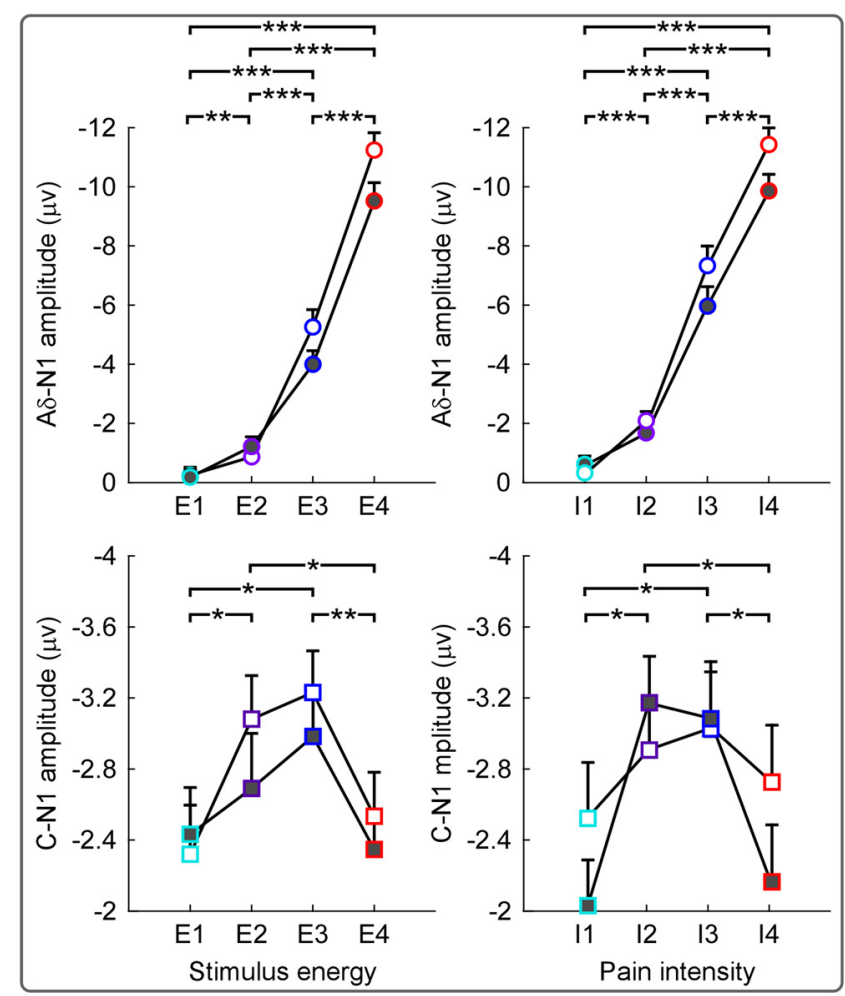

Figure 6. Dependence of human $\mathrm{A} \delta$-N1 and C-N1 amplitudes on stimulus energy and perceived pain. Group-level amplitudes of A $\delta$-N1 (top, circles) and C-N1 (bottom, squares) waves elicited by stimulation of the left (open symbols) and right (solid symbols) hand dorsum at different levels of stimulus energy (left: E1-E4) and different categories of pain intensity (right: 11-14). Error bars indicate SEM across subjects. Note that $A \delta$-N1 amplitudes increase monotonically with stimulus energy or pain intensity, whereas $\mathrm{C}-\mathrm{N} 1$ amplitudes are maximal at moderate levels of stimulus energy (E2 and E3) or pain intensity (I2 and I3). ${ }^{*} p<0.05,{ }^{* *} p<0.01$, ${ }^{* * *} p<0.001$.

response elicited by right and left hindpaw stimulation (210-230 ms; Fig. 7, right) were more centrally distributed.

\section{Isolation of the C-N1 wave}

Similar to human A $\delta$ - and C-LEP data, the widespread scalp distribution of the main vertex C-LEP components makes the detection of the early lateralized neural activities as a separate peak difficult (Xia et al., 2016). To reduce the influence of widespread activities and thus enhance spatially discrete activities, we average referenced the data (Bertrand et al., 1985). This allows to visualize the first two negative waves $(\mathrm{N} 1, \mathrm{~N} 2)$ and the third positive wave (P2) as separate deflections (Xia et al., 2016). The N1 wave was optimally detected from electrode RFR (after left 
Forepaw stimulation

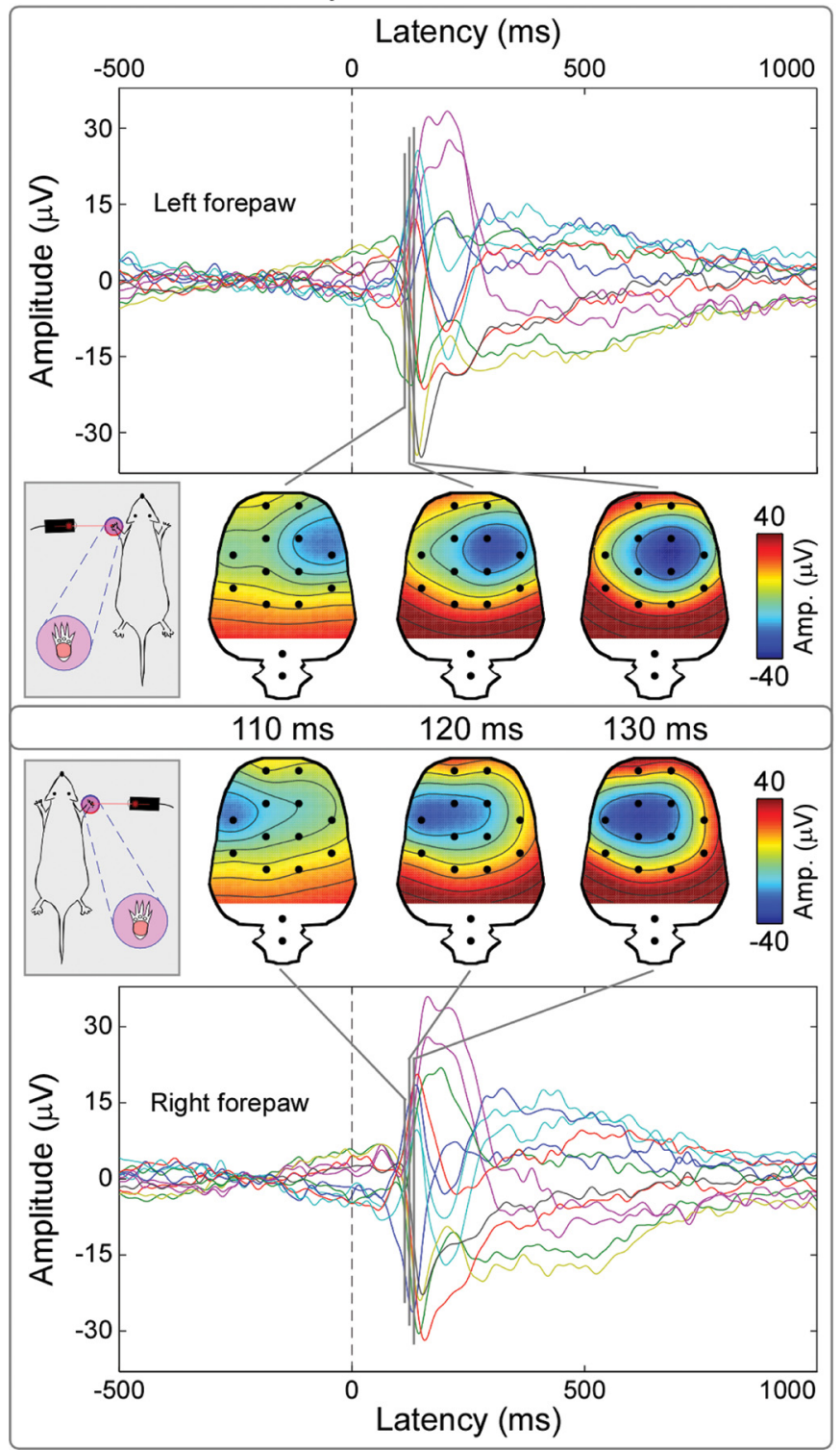

Hindpaw stimulation

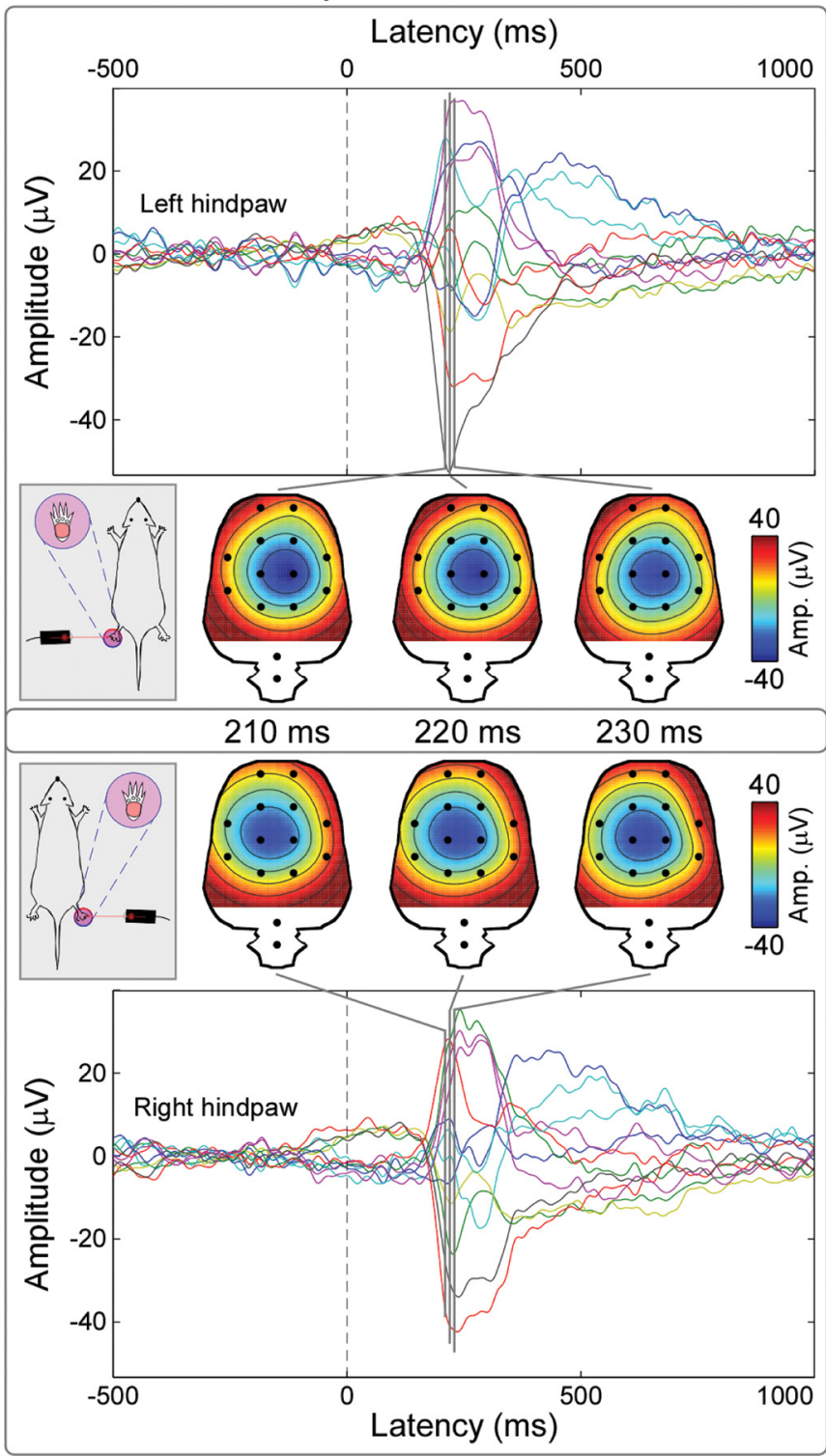

Figure 7. S1 contribution to the earliest part of rat C-LEPs elicited by stimulation of the left and right (top and bottom) forepaw and hindpaw (left and right). Grand average waveforms from all electrodes are plotted in different colors and superimposed. Series of scalp topographies of the earliest part of C-LEPs (110-130 ms, forepaw; $210-230$ ms, hindpaw) are displayed at 10-ms intervals. Note that the scalp topographies of the earliest part of the C-LEPs elicited by forepaw stimulation display a negativity strongly contralateral to the stimulated side, whereas the scalp topographies of the earliest part of C-LEPs elicited by hindpaw stimulation, albeit contralateral, are more centrally distributed. These topographies are compatible with the somatotopical organization of the S1, and indicate that $S 1$ contributes to the early part of the brain response evoked by C-fiber stimulation.

forepaw stimulation), LFL (after right forepaw stimulation), PR1 (after left hindpaw stimulation), and PL1 (after right hindpaw stimulation) (Fig. 8). Peak latency and amplitude of the N1 wave were as follows: $125 \pm 11 \mathrm{~ms},-35.7 \pm 6.2 \mu \mathrm{V}$ (left forepaw); $125 \pm 3 \mathrm{~ms},-29.3 \pm 6.0 \mu \mathrm{V}$ (right forepaw); $230 \pm 7 \mathrm{~ms}$, $-42.0 \pm 6.5 \mu \mathrm{V}$ (left hindpaw); and $230 \pm 6 \mathrm{~ms},-34.3 \pm 5.4 \mu \mathrm{V}$ (right hindpaw).

Dependence of rat C-N1 amplitudes on stimulus energy

In striking contrast to the human data, the amplitude of the rat C-N1 displayed a monotonic relationship with stimulus energy (Fig. 9). Two-way repeated-measures ANOVA with factors stimulus energy (five levels: E1'-E5') and stimulated side (four levels: left and right forepaw and hindpaw) showed that C-N1 amplitudes were significantly modulated by stimulus energy $\left(F_{(4,44)}=\right.$ $\left.41.41, p<0.001, \eta_{\mathrm{p}}^{2}=0.79\right)$, but not by stimulated side $\left(F_{(3,33)}=\right.$
1.93, $\left.p=0.14, \eta_{\mathrm{p}}^{2}=0.15\right)$ or their interaction $\left(F_{(12,132)}=1.64\right.$, $\left.p=0.09, \eta_{\mathrm{p}}^{2}=0.11\right)$. Post hoc pairwise comparisons revealed that $\mathrm{C}-\mathrm{N} 1$ amplitudes at E3', E4', and E5' were significantly larger than those at E1' and E2' ( $p<0.05$; Fig. 9), indicating a strong positive relationship between stimulus energy and C-N1 amplitude.

\section{Discussion}

\section{Main findings}

We describe for the first time the somatotopical organization and the stimulus-response functions of the electrocortical responses elicited in the $S 1$ by selective stimulation of small-myelinated A $\delta$ and unmyelinated $\mathrm{C}$ afferents in humans and rats. We obtained five main results.

First, both in human and rat recordings, the topographical distribution of the earliest part of the cortical response elicited by C-fiber input (C-LEPs) was clearly dependent on the stimu- 
Forepaw stimulation

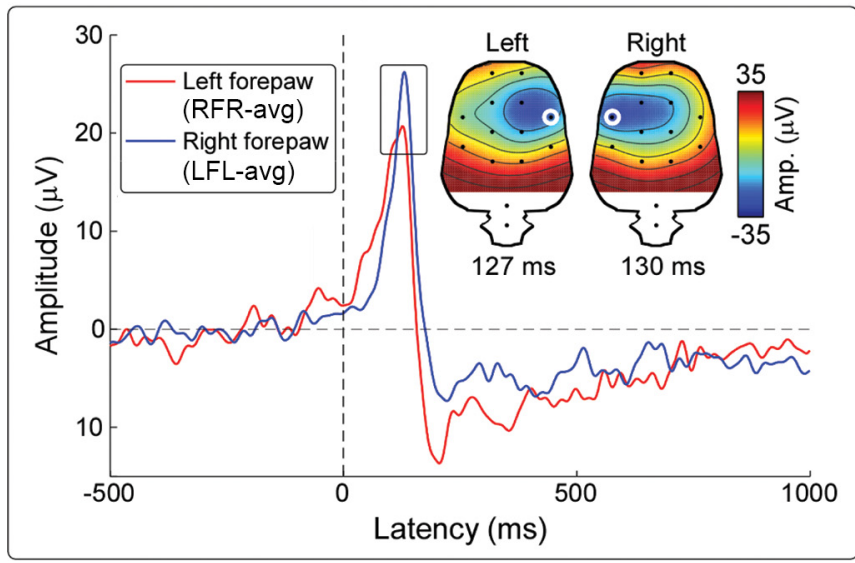

Hindpaw stimulation

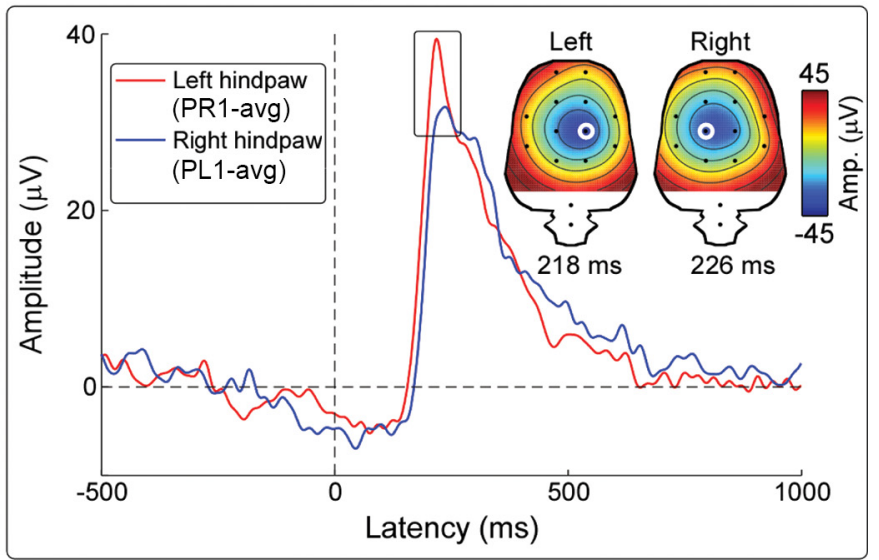

Figure 8. Isolation of C-N1 waves in rats. Grand-average C-N1 waves elicited by the stimulation of the left (red waveforms) and right (blue waveforms) forepaw (left panel) and hindpaw (right panel). The (-N1 was optimally detected from the electrodes highlighted in white: RFR after left forepaw stimulation, LFL after right forepaw stimulation, PR1 after left hindpaw stimulation, and PL1 after right hindpaw stimulation. Scalp topographies at peak latency show a maximum contralateral to the stimulated side, clearly lateralized in the response elicited by forepaw stimulation and less lateralized in the response elicited by hindpaw stimulation.

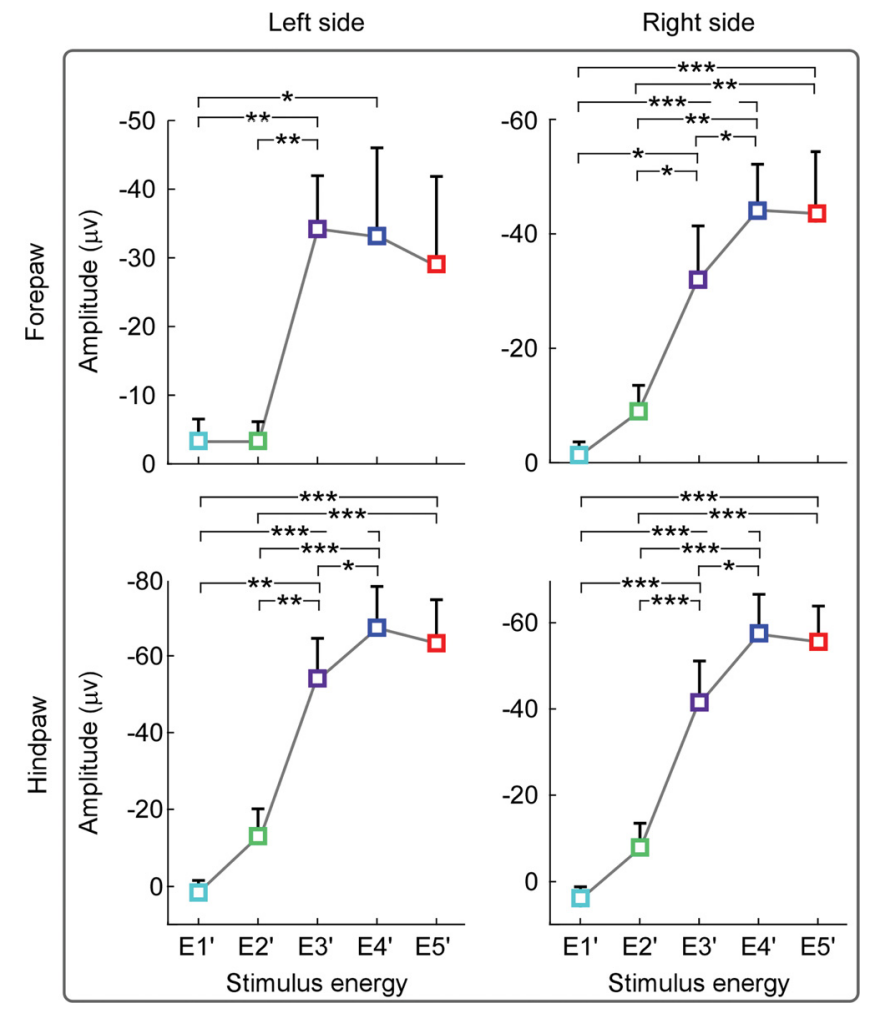

Figure 9. Dependence of rat C-N1 amplitudes on stimulus energy. Group-level amplitudes of C-N1 waves elicited by stimulation of the left and right forepaw (top) and hindpaw (bottom) at different levels of stimulus energy (E1'-E5'). Error bars indicate SEM across subjects. Note that, whereas human (-N1 amplitude is maximal at moderate level of stimulus energy (Fig. 6), rat C-N1 amplitude increases quasimonotonically with stimulus energy and only plateaus at E4' $E 5^{\prime} .{ }^{*} p<0.05,{ }^{* *} p<0.01,{ }^{* * *} p<0.001$.

lated limb (Figs. 2, 7). When the stimulus was delivered to the hand or the forepaw, the response displayed a negative maximum in the hemisphere contralateral to the stimulation side. In contrast, when the stimulus was delivered to the foot or the hindpaw, the response was more centrally distributed (Figs. 2, 7).

Second, source analysis of human EEG confirmed that the cortical sources of the earliest part of C-LEPs were located in the postcentral gyrus, in positions compatible with the representations of the stimulated body district within S1 (Fig. 3).

Third, in human EEG, a bipolar Cc-Fz montage allowed detecting this $\mathrm{S} 1$ activity as a distinct early deflection (C-N1 wave), peaking at 710-730 $\mathrm{ms}$ after hand stimulation (Fig. 4). In contrast, a C-N1 could not be clearly isolated after foot stimulation because of the more medial foot representation within S1 results in a strong spatial and temporal overlap with the large amplitude C-N2 (Fig. 1). Different from human recordings, in rat ECoG a clear C-N1 could be isolated after both forepaw and hindpaw stimulation (Fig. 8), because of the different representation of the body surface within $\mathrm{S} 1$.

Fourth, stimulus-response functions were different in humans and rats. In humans, C-N1 had maximal amplitude at moderate stimulus energy and pain intensity (Fig. 6), whereas in rats C-N1 amplitude increased quasimonotonically with stimulus energy (Fig. 9). The difference in stimulus-response functions was caused by the combination of the across-species difference in thermal sensitivity of A $\delta$ nociceptors (Hu et al., 2015) with the dependence of these electrocortical responses in the time domain on stimulus relevance (Iannetti et al., 2008; Mouraux and Iannetti, 2009).

Finally, there was a decoupling between the activity of the S1 (indexed by $\mathrm{C}-\mathrm{N} 1$ in human recordings) and the activity of the supramodal generators of N2-P2 vertex waves (Mouraux and Iannetti, 2009): the C-N1 amplitude was positively correlated with the amplitude of the A $\delta$-N1 wave, but not correlated with the amplitude of the other vertex waves: $\mathrm{C}-\mathrm{N} 2, \mathrm{C}-\mathrm{P} 2, \mathrm{~A} \delta$-N2, and $\mathrm{A} \delta$-P2 (Fig. 5). This finding highlights the functional dissociation between the generators of somatosensory-specific (C-N1 and $\mathrm{A} \delta$ $\mathrm{N} 1)$ and supramodal waves (A $\delta$-N2/P2 and C-N2/P2).

Detecting $\mathrm{C}$-fiber responses in the $\mathrm{S} 1$ of humans and rodents Stimulus-response functions of C-fiber responses in the S1 of rats and humans were clearly different. Whereas in humans the $\mathrm{C}-\mathrm{N} 1$ wave was maximal at moderate levels of stimulus energy and pain intensity (Fig. 6), in rats it increased monotonically with stimulus energy and only plateaued at the highest stimulus energy (Fig. 9). To understand this difference, it is important to consider two physiological aspects: (1) the functional significance of the electrocortical responses elicited by sudden and fast-rising sen- 
sory stimuli and (2) the different heat sensitivity of A $\delta$ skin nociceptors in rodents and humans.

The large brain potentials detected in EEG and ECoG recordings in response to sudden sensory stimuli do not always faithfully reflect the intensity of the afferent peripheral input; instead, they are strongly determined by contextual factors such as stimulus saliency (Iannetti et al., 2008; Mouraux and Iannetti, 2009; Ronga et al., 2013). This simple concept explains why, in humans, the C-fiber response (e.g., the C-N1; Figs. 1, 2, 3, 4) is larger when preceded by an $\mathrm{A} \delta$-fiber response elicited by stimuli of moderate energy and pain intensity (E2-E3, I2-I3; Fig. 6), whereas it becomes smaller when preceded by a large $\mathrm{A} \delta$-fiber response elicited by stimuli of high energy (E4) (Hu et al., 2014b). For this reason, the $\mathrm{C}$-fiber response has for a long time been considered to be detectable only when the concomitant activation of $\mathrm{A} \delta$-fibers is avoided or reduced (Bromm and Treede, 1983; Bragard et al., 1996; Mouraux et al., 2003).

This reasoning does not apply to the C-fiber ECoG responses measured in rats because $\mathrm{A} \delta$-nociceptors have different heat sensitivity in rodents and humans. In rats, as demonstrated by recordings from peripheral axons and spinal cord neurons (Devor et al., 1982; Lynn and Shakhanbeh, 1988; Sikandar et al., 2013), estimates of conduction velocity of peripheral afferents (Jiang et al., 2007), and nocifensive behaviors (Fan et al., 2009), A $\delta$ units are virtually insensitive to heat. For this reason, in rats, there is no $\mathrm{A} \delta$-fiber response to heat, and the $\mathrm{ECoG}$ response elicited by the C-fiber afferent volley is monotonically graded with the energy of the applied stimulus (Fig. 9).

\section{Unmyelinated nociceptive input elicits somatotopically organized responses in $\mathrm{S} 1$}

Although strongly debated only a few years ago (Bushnell et al., 1999; Ploner et al., 2002), there is now compelling evidence that nociceptive stimulation elicits robust responses in the S1. To settle the issue of whether $\mathrm{S} 1$ responds to nociceptive input, the use of somatosensory stimuli that activate $\mathrm{A} \delta$ - and $\mathrm{C}$-nociceptors selectively, that is, without the coactivation of non-nociceptive $\mathrm{A} \beta$ fibers (Baumgärtner et al., 2005), has been decisive. Psychophysically, selective stimulation of $A \delta$-afferents has allowed revealing that first pain and touch have remarkably similar spatial acuity across the body (Mancini et al., 2013). The same A $\delta$-selective laser stimulation has allowed the identification of somatosensory-specific deflections in the human EEG, from the seminal evidence that $\mathrm{S} 1$ contributes to the N1 wave (Tarkka and Treede, 1993) to the comprehensive characterization of $\mathrm{N} 1$ topography and underling sources (Valentini et al., 2012; Hu et al., 2014b). Finally, phase-encoded fMRI combined with the same laser stimuli has allowed demonstrating the existence of fine-grained maps of individual digits in the human S1 (Mancini et al., 2012).

Whether and how S1 also responds to unmyelinated C-fiber input remains an open issue. Traditionally, second pain consequent to the arrival of the afferent volley transmitted by slowconducting C-units is considered to be less well localized than the A $\delta$-mediated first pain, although rigorous studies of spatial acuity for second pain are lacking. Some investigators have suggested that $\mathrm{C}$ input elicits responses in the area $3 \mathrm{a}$ of S1 (Vierck et al., 2013), in contrast to the responses to A $\delta$ input, which are localized in areas 3b/1 (Whitsel et al., 2009; Vierck et al., 2013). However, these studies used long thermal stimuli delivered through mechanical probes that unavoidably coactivate touchrelated $\mathrm{A} \beta$-afferents. It is therefore difficult to rule out that these S1 responses are contributed by the concomitant tactile input: indeed, as detailed previously (Nahra and Plaghki, 2005), even if the applied tactile input is constant, the heating of the thermode can cause a transient response still mediated by the tactile input.

Here, we used topographical analysis and source modeling of human EEG and rat ECoG data to provide converging and across-species evidence that the earliest part of the cortical response elicited by C-fiber stimulation is generated in the S1 contralateral to the stimulated side, and that this response follows the representation of the body surface within S1 (Penfield and Boldrey, 1937; Kandel et al., 2013). The observation that C-N1 amplitude is maximally correlated with the amplitude of the $\mathrm{A} \delta$-N1 wave, but not with the amplitude of the other vertex waves (A $\delta$-N2/P2 and C-N2/P2; Fig. 5), provides additional evidence that the cortical generator of $\mathrm{C}-\mathrm{N} 1$ is similar, if not identical, to that of $\mathrm{A} \delta$-N1, which has been repeatedly shown to be largely contributed by the contralateral S1 (Treede et al., 1988; Valentini et al., 2012; Hu et al., 2014a). However, the limited spatial resolution of both ECoG and scalp EEG (Buzsáki et al., 2012; Gratiy et al., 2017) does not allow excluding the possibility that the C-N1 response (as well as the $\mathrm{A} \delta$-N1 response; Treede et al., 1988; Valentini et al., 2012) is contributed by sources in the primary motor cortex, whose topographical arrangement follows closely that of S1 (Penfield and Boldrey, 1937). Direct recording of local field potentials is a more adequate approach to address this issue.

C-fiber afferents are the phylogenetically oldest of the somatosensory system (Franzén et al., 1996; van Bijsterveld et al., 2003). Their main function is to inform the CNS of potentially noxious environmental stimuli (Julius and Basbaum, 2001). It is therefore unsurprising that the $\mathrm{C}$-fiber conveys at least some information about the spatial location of noxious stimulation across the body surface also considering that even the lateral periaqueductal gray receives somatotopically organized nociceptive projections (Holstege et al., 1996; Benarroch, 2012). The somatotopically organized projections to the $S 1$ are likely to be a prerequisite for deploying spatially-coherent defensive moments. Although the present results provide compelling evidence for a gross somatotopy within S1, the resolution of the spatial acuity of the C-fiber system remains to be fully characterized.

\section{References}

Basbaum AI, Bushnell MC (2009) Science of pain. Oxford, UK: Academic. Baumgärtner U, Cruccu G, Iannetti GD, Treede RD (2005) Laser guns and hot plates. Pain 116:1-3. CrossRef Medline

Benarroch EE (2012) Periaqueductal gray: an interface for behavioral control. Neurology 78:210-217. CrossRef Medline

Benjamini Y, Hochberg Y (1995) Controlling the false discovery rate: a practical and powerful approach to multiple testing. J Roy Stat Soc B Met 57:289-300.

Bertrand O, Perrin F, Pernier J (1985) A theoretical justification of the average reference in topographic evoked potential studies. Electroencephalography and clinical neurophysiology 62:462-464. CrossRef Medline

Bragard D, Chen AC, Plaghki L (1996) Direct isolation of ultra-late (Cfibre) evoked brain potentials by $\mathrm{CO} 2$ laser stimulation of tiny cutaneous surface areas in man. Neurosci Lett 209:81-84. CrossRef Medline

Bromm B, Treede RD (1983) CO2 laser radiant heat pulses activate C nociceptors in man. Pflugers Arch 399:155-156. CrossRef Medline

Bromm B, Treede RD (1984) Nerve fibre discharges, cerebral potentials and sensations induced by CO2 laser stimulation. Hum Neurobiol 3:33-40. Medline

Bushnell MC, Duncan GH, Hofbauer RK, Ha B, Chen JI, Carrier B (1999) Pain perception: is there a role for primary somatosensory cortex? Proc Natl Acad Sci U S A 96:7705-7709. CrossRef Medline

Buzsáki G, Anastassiou CA, Koch C (2012) The origin of extracellular fields and currents-EEG, ECoG, LFP and spikes. Nat Rev Neurosci 13:407-420. CrossRef Medline

Delorme A, Makeig S (2004) EEGLAB: an open source toolbox for analysis 
of single-trial EEG dynamics including independent component analysis. J Neurosci Methods 134:9-21. CrossRef Medline

Devor M, Carmon A, Frostig R (1982) Primary afferent and spinal sensory neurons that respond to brief pulses of intense infrared laser radiation: a preliminary survey in rats. Exp Neurol 76:483-494. CrossRef Medline

Downar J, Crawley AP, Mikulis DJ, Davis KD (2000) A multimodal cortical network for the detection of changes in the sensory environment. Nat Neurosci 3:277-283. CrossRef Medline

Fan RJ, Shyu BC, Hsiao S (1995) Analysis of nocifensive behavior induced in rats by CO2 laser pulse stimulation. Physiol Behav 57:1131-1137. CrossRef Medline

Fan RJ, Kung JC, Olausson BA, Shyu BC (2009) Nocifensive behaviors components evoked by brief laser pulses are mediated by C fibers. Physiol Behav 98:108-117. CrossRef Medline

Franzén O, Johansson R, Terenius L (1996) Somesthesis and the neurobiology of the somatosensory cortex. Basel, Switzerland: Birkhäuser.

Garcia-Larrea L, Frot M, Valeriani M (2003) Brain generators of laserevoked potentials: from dipoles to functional significance. Neurophysiol Clin 33:279-292. CrossRef Medline

Gratiy SL, Halnes G, Denman D, Hawrylycz MJ, Koch C, Einevoll GT, Anastassiou CA (2017) From Maxwell's equations to the theory of currentsource density analysis. Eur J Neurosci 45:1013-1023. CrossRef Medline

Hess A (2015) Importance of knowing your stimulation paradigm: methodological considerations on laser-evoked pain responses in rats and humans. Pain 156:2404-2405. CrossRef Medline

Holstege G, Bandler R, Saper CB (1996) The emotional motor system. Prog Brain Res 107:3-6. CrossRef Medline

Hu L, Mouraux A, Hu Y, Iannetti GD (2010) A novel approach for enhancing the signal-to-noise ratio and detecting automatically event-related potentials (ERPs) in single trials. Neuroimage 50:99-111. CrossRef Medline

Hu L, Valentini E, Zhang ZG, Liang M, Iannetti GD (2014a) The primary somatosensory cortex contributes to the latest part of the cortical response elicited by nociceptive somatosensory stimuli in humans. Neuroimage 84:383-393. CrossRef Medline

Hu L, Cai MM, Xiao P, Luo F, Iannetti GD (2014b) Human brain responses to concomitant stimulation of adelta and C nociceptors. J Neurosci 34 : 11439-11451. CrossRef Medline

Hu L, Xia XL, Peng WW, Su WX, Luo F, Yuan H, Chen AT, Liang M, Iannetti G (2015) Was it a pain or a sound? Across-species variability in sensory sensitivity. Pain 156:2449-2457. CrossRef Medline

Iannetti GD, Truini A, Romaniello A, Galeotti F, Rizzo C, Manfredi M, Cruccu G (2003) Evidence of a specific spinal pathway for the sense of warmth in humans. J Neurophysiol 89:562-570. CrossRef Medline

Iannetti GD, Leandri M, Truini A, Zambreanu L, Cruccu G, Tracey I (2004) Adelta nociceptor response to laser stimuli: selective effect of stimulus duration on skin temperature, brain potentials and pain perception. Clin Neurophysiol 115:2629-2637. CrossRef Medline

Iannetti GD, Hughes NP, Lee MC, Mouraux A (2008) Determinants of laser-evoked EEG responses: pain perception or stimulus saliency? J Neurophysiol 100:815-828. CrossRef Medline

Jiang N, Cooper BY, Nemenov MI (2007) Non-invasive diode laser activation of transient receptor potential proteins in nociceptors. Proc SPIE Int Soc Opt Eng 6428:642809. CrossRef Medline

Julius D, Basbaum AI (2001) Molecular mechanisms of nociception. Nature 413:203-210. CrossRef Medline

Kandel ER, Schwartz JH, Jessell TM, Siegelbaum S, Hudspeth AJ (2013) Principles of neural science, Ed 5. New York, NY: McGraw-Hill.

Kunde V, Treede RD (1993) Topography of middle-latency somatosensory evoked potentials following painful laser stimuli and non-painful electrical stimuli. Electroencephalogr Clin Neurophysiol 88:280-289. CrossRef Medline

Lee MC, Mouraux A, Iannetti GD (2009) Characterizing the cortical activity through which pain emerges from nociception. J Neurosci 29:7909-7916. CrossRef Medline

Lewis T, Pochin EE (1937) The double pain response of the human skin to a single stimulus. Clin Sci 3:37-67.

Lopes da Silva F (2004) Functional localization of brain sources using EEG and/or MEG data: volume conductor and source models. Magn Reson Imaging 22:1533-1538. CrossRef Medline

Lynn B, Shakhanbeh J (1988) Properties of A delta high threshold mechanoreceptors in the rat hairy and glabrous skin and their response to heat. Neurosci Lett 85:71-76. CrossRef Medline
Magerl W, Ali Z, Ellrich J, Meyer RA, Treede RD (1999) C- and A delta-fiber components of heat-evoked cerebral potentials in healthy human subjects. Pain 82:127-137. CrossRef Medline

Mancini F, Haggard P, Iannetti GD, Longo MR, Sereno MI (2012) Finegrained nociceptive maps in primary somatosensory cortex. J Neurosci 32:17155-17162. CrossRef Medline

Mancini F, Sambo CF, Ramirez JD, Bennett DL, Haggard P, Iannetti GD (2013) A fovea for pain at the fingertips. Curr Biol 23:496-500. CrossRef Medline

Mouraux A, Iannetti GD (2008) Across-trial averaging of event-related EEG responses and beyond. Magn Reson Imaging 26:1041-1054. CrossRef Medline

Mouraux A, Iannetti GD (2009) Nociceptive laser-evoked brain potentials do not reflect nociceptive-specific neural activity. J Neurophysiol 101: 3258-3269. CrossRef Medline

Mouraux A, Guérit JM, Plaghki L (2003) Non-phase locked electroencephalogram (EEG) responses to CO2 laser skin stimulations may reflect central interactions between A partial partial differential- and C-fibre afferent volleys. Clin Neurophysiol 114:710-722. CrossRef Medline

Nahra H, Plaghki L (2005) Innocuous skin cooling modulates perception and neurophysiological correlates of brief $\mathrm{CO} 2$ laser stimuli in humans. Eur J Pain 9:521-530. CrossRef Medline

Penfield W, Boldrey E (1937) Somatic motor and sensory representation in the cereb cortex of man as studied by electrical stimulation. Brain 60:389443. CrossRef

Ploner M, Gross J, Timmermann L, Schnitzler A (2002) Cortical representation of first and second pain sensation in humans. Proc Natl Acad Sci U S A 99:12444-12448. CrossRef Medline

Ronga I, Valentini E, Mouraux A, Iannetti GD (2013) Novelty is not enough: laser-evoked potentials are determined by stimulus saliency, not absolute novelty. J Neurophysiol 109:692-701. CrossRef Medline

Scherg M, Ebersole JS (1993) Models of brain sources. Brain Topogr 5:419_ 423. CrossRef Medline

Shim B, Kim DW, Kim BH, Nam TS, Leem JW, Chung JM (2005) Mechanical and heat sensitization of cutaneous nociceptors in rats with experimental peripheral neuropathy. Neuroscience 132:193-201. CrossRef Medline

Sikandar S, Ronga I, Iannetti GD, Dickenson AH (2013) Neural coding of nociceptive stimuli-from rat spinal neurones to human perception. Pain 154:1263-1273. CrossRef Medline

Tarkka IM, Treede RD (1993) Equivalent electrical source analysis of painrelated somatosensory evoked potentials elicited by a $\mathrm{CO} 2$ laser. J Clin Neurophysiol 10:513-519. CrossRef Medline

Treede RD, Kief S, Hölzer T, Bromm B (1988) Late somatosensory evoked cerebral potentials in response to cutaneous heat stimuli. Electroencephalogr Clin Neurophysiol 70:429-441. CrossRef Medline

Treede RD, Meyer RA, Campbell JN (1998) Myelinated mechanically insensitive afferents from monkey hairy skin: heat-response properties. J Neurophysiol 80:1082-1093. CrossRef Medline

Tu Y, Zhang Z, Tan A, Peng W, Hung YS, Moayedi M, Iannetti GD, Hu L (2016) Alpha and gamma oscillation amplitudes synergistically predict the perception of forthcoming nociceptive stimuli. Hum Brain Mapp 37:501-514. CrossRef Medline

Valentini E, Hu L, Chakrabarti B, Hu Y, Aglioti SM, Iannetti GD (2012) The primary somatosensory cortex largely contributes to the early part of the cortical response elicited by nociceptive stimuli. Neuroimage 59:15711581. CrossRef Medline

van Bijsterveld OP, Kruize AA, Bleys RL (2003) Central nervous system mechanisms in Sjogren's syndrome. Br J Ophthalmol 87:128-130. CrossRef Medline

Vierck CJ, Whitsel BL, Favorov OV, Brown AW, Tommerdahl M (2013) Role of primary somatosensory cortex in the coding of pain. Pain 154: 334-344. CrossRef Medline

Whitsel BL, Favorov OV, Li Y, Quibrera M, Tommerdahl M (2009) Area 3a neuron response to skin nociceptor afferent drive. Cereb Cortex 19:349366. CrossRef Medline

Xia XL, Peng WW, Iannetti GD, Hu L (2016) Laser-evoked cortical responses in freely-moving rats reflect the activation of C-fibre afferent pathways. Neuroimage 128:209-217. CrossRef Medline

Zhang ZG, Hu L, Hung YS, Mouraux A, Iannetti GD (2012) Gamma-band oscillations in the primary somatosensory cortex-a direct and obligatory correlate of subjective pain intensity. J Neurosci 32:7429-7438. CrossRef Medline 